\title{
Synthesis and Biological Evaluation of Novel Furozan-Based Nitric Oxide-Releasing Derivatives of 23-Hydroxy Betulinic Acid and 3-oxo-23- hydroxybetulinic acid as Potential Anti-Tumor Agents
}

\author{
Jie Liu ${ }^{1,3}$, Fei Sun ${ }^{1,2}$, Hengyuan Zhang ${ }^{1,2}$, Hao Cai ${ }^{1,2}$, Hequan Yao ${ }^{1,2}$, Weijia Xie ${ }^{1,2}$, Jieyun Jiang ${ }^{4}$, Xiaoming Wu ${ }^{1,2}$ and Jinyi Xu ${ }^{1,2 *}$ \\ ${ }^{1}$ State Key Laboratory of Natural Medicines, China Pharmaceutical University, 24 Tong Jia Xiang, Nanjing 210009, PR China \\ ${ }^{2}$ Department of Medicinal Chemistry, China Pharmaceutical University, 24 Tong Jia Xiang, Nanjing 210009, PR China \\ ${ }^{3}$ Department of Organic Chemistry, China Pharmaceutical University, 24 Tong Jia Xiang, Nanjing, 210009, PR China \\ ${ }^{4}$ Department of Microbiology, Immunology and Molecular Genetics, University of Kentucky College of Medicine, 800 Rose Street, Lexington, KY 40536, USA
}

\begin{abstract}
To search for novel nitric oxide (NO)-releasing anti-tumor agents, two series of furoxan-based NO-releasing derivatives of 23-Hydroxybetulinic acid and 3-oxo-23-hydroxybetulinic acid were designed and synthesized. The nitrate/nitrite levels in the cell lysates were assayed and the results showed that these derivatives could produce high levels of NO in vitro. Then the antiproliferative activity of these hybrids against four human cancer cell lines was further determined, among which, compound 20 a was the most promising derivative with an $\mathrm{IC}_{50}$ under $10 \mu \mathrm{M}$ on all tested cell lines. The preliminary structure-activity relationships were concluded based on present experimental data.
\end{abstract}

Keywords: 23-Hydroxy betulinic acid; NO-donor; Furozan; Antitumor activity

\section{Introduction}

Lupane triterpenoids such as betulinic acid (Figure 1) are prevalent in natural sources and have various biological activities. 23-Hydroxybetulinic acid (Figure 1) was isolated from the roots of a Chinese medicinal herb Pulsatilla chinensis (Bge) Regel, which has a very similar structure and pharmacological activity to betulinic acid [1-3]. A great deal of investigations on the structural modifications of betulinic acid and 23-hydroxybetulinic acid were carried out, and many derivatives with excellent anti-HIV and anti-tumor activities have been obtained [4-6]. Meanwhile, pharmacological studies suggested that 3-oxo-23hydroxybetulinic acid (3) (Figure 1) had stronger cytotoxic activity on murine melanoma B16 cells $\left(\mathrm{IC}_{50}=22.5 \mu \mathrm{g} / \mathrm{ml}\right)$ than 23-hydroxybetulinic acid and betulinic acid $\left(\mathrm{IC}_{50}=32\right.$ and $76 \mu \mathrm{g} / \mathrm{ml}$, respectively) [7]. On another hand, our previous study showed that the polarity and length of the chain in C-28 had an important impact on the anti-tumor activity. These results motivated us to undertake further modifications of the C-28 of 23-Hydroxybetulinic acid, and more intensive SARs have been obtained $[8,9]$.

Nitric oxide (NO), a free radical gas, is a key mediator involved in many physiological and pathological processes. High levels of NO and its metabolic derivatives, the reactive nitrogen species (RNS) and reactive oxygen species (ROS), can modify functional proteins by S-nitrosylation, nitration, and disulfide formation, leading to bio-regulation, inactivation, and cytotoxicity, particularly in tumor cells [10-12]. Therefore, NOreleasing compounds as anti-cancer agents have been investigating for cancer therapy at clinic $[13,14]$. Furoxans are thermally stable compounds and represent one class of NO donors that can produce high levels of $\mathrm{NO}$ and exhibit strong anti-cancer activity $[15,16]$.

Inspired by the obtained interesting results of our previous studies, in which an NO-donor moiety was connected to a 'native' molecule for the purpose of enhancing its therapeutic impact $[17,18]$, in this study, two series of novel furozan-based nitric oxide-releasing derivatives of 23-hydroxybetulinic acid and its analogue 3-oxo-23-hydroxybetulinic acid were designed and synthesized.

\section{Methods and Materials}

\section{Synthesis}

General: Commercially available reagents and solvents were used without further purification. Column chromatography was carried out on Merck silica gel 60 (200-300 mesh). ${ }^{1} \mathrm{H}$ NMR spectra were recorded with $300 \mathrm{MHz}$ spectrometers in the indicated solvents (TMS as internal standard). Chemical shifts were reported in parts per million (ppm, $\delta$ ) downfield from tetramethylsilane. Proton coupling patterns are described as singlet $(\mathrm{s})$, doublet $(\mathrm{d})$, triplet $(\mathrm{t})$, quartet $(\mathrm{q})$, double doublet (dd), multipet $(\mathrm{m})$ and broad (br). Low-resolution mass spectra (LRMS) were measured on Agilent QTOF 6520.

Synthetic Procedures/Analytical Data of Compounds: The synthetic method and physicochemical date of the compounds 10a-i were disclosed in our previous report [17].

1) Benzyl 3,23-dihydroxy-lup-20(29)-en-28-oate (11): To a mixture of 23-Hydroxybetulinic acid (2) (1.00 g, $2.1 \mathrm{mmol})$ and $\mathrm{K}_{2} \mathrm{CO}_{3}(1.00 \mathrm{~g}, 7.2 \mathrm{mmol})$ in DMF $(20 \mathrm{~mL})$ was added benzyl chloride

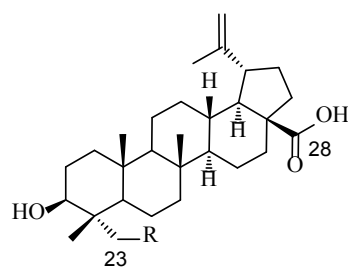

Betulinic acid (1): $\mathrm{R}=\mathrm{H}$

23-Hydroxybetulinic acid (2): $\mathrm{R}=\mathrm{OH}$

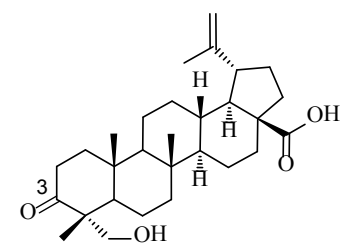

3-oxo-23-hydroxybetulinic acid (3)
Figure 1: Structure of betulinic acid (1), 23-hydroxybetulinic acid (2) and 3-oxo-23-hydroxybetulinic acid (3).

*Corresponding author: Jinyi $\mathrm{Xu}$, Department of Medicinal Chemistry, China Pharmaceutical University, 24 Tong Jia Xiang, Nanjing 210009, PR China, Tel: +86 25 83271445; E-mail: jinyixu@china.com

Received November 21, 2014; Accepted January 15, 2015; Published January 17,2015

Citation: Liu J, Sun F, Zhang H, Cai H, Yao H, et al. (2015) Synthesis and Biological Evaluation of Novel Furozan-Based Nitric Oxide-Releasing Derivatives of 23-Hydroxy Betulinic Acid and 3-oxo-23-hydroxybetulinic acid as Potential AntiTumor Agents. Med chem 5: 028-036. doi:10.4172/2161-0444.1000239

Copyright: @ $2015 \mathrm{Liu} \mathrm{J}$, et al. This is an open-access article distributed under the terms of the Creative Commons Attribution License, which permits unrestricted use, distribution, and reproduction in any medium, provided the original author and source are credited. 
Citation: Liu J, Sun F, Zhang H, Cai H, Yao H, et al. (2015) Synthesis and Biological Evaluation of Novel Furozan-Based Nitric Oxide-Releasing Derivatives of 23-Hydroxy Betulinic Acid and 3-oxo-23-hydroxybetulinic acid as Potential Anti-Tumor Agents. Med chem 5: 028-036. doi:10.4172/2161-0444.1000239

$(0.3 \mathrm{ml}, 2.5 \mathrm{mmol})$ at room temperature for $12 \mathrm{~h}$. Then the reaction mixture was filtered, and washed with $\operatorname{DMF}(5 \mathrm{~mL} \times 3)$. The filtrate was poured into ice-water to give a white precipitate. The precipitate was filtered, washed with water, and dried to give $11(1.07 \mathrm{~g}, 90 \%)$, which was almost a pure product, and was used for the next reaction without further purification. Pure product was obtained by recrystallization of the crude product from EtOH. ESI-MS $m / z: 563.3[\mathrm{M}+\mathrm{H}]^{+}, 585.3[\mathrm{M}$ $+\mathrm{Na}]^{+}, 601.4[\mathrm{M}+\mathrm{K}]^{+}$

2) Benzyl 3-hydroxy-23-t-butyldimethylsilyloxy-lup-20(29)en-28-oate (12): To a solution of $11(1.00 \mathrm{~g}, 1.8 \mathrm{mmol})$ in $\mathrm{CH}_{2} \mathrm{Cl}_{2}(30$ $\mathrm{mL}$ ) was added TBSCl $(0.36 \mathrm{~g}, 2.4 \mathrm{mmol})$, DMAP $(0.3 \mathrm{~g}, 2.5 \mathrm{mmol})$ at room temperature for $4 \mathrm{~h}$. After $\mathrm{CH}_{2} \mathrm{Cl}_{2}$ was removed by evaporation in vacuo, the residue was acidified with $10 \% \mathrm{HCl}(20 \mathrm{~mL})$ and extracted with EtOAc. The combined extract was washed with saturated brine (30 $\mathrm{mL} \times 3$ ), dried over $\mathrm{Na}_{2} \mathrm{SO}_{4}$, filtered, and concentrated in vacuo to afford a yellow oil, which was purified by column chromatography (petroleum ether-EtOAc (20:1)) to give 12 as a white solid (1.11 g, 92\%). ${ }^{1} \mathrm{H}-\mathrm{NMR}\left(\mathrm{CDCl}_{3}, 300 \mathrm{MHz}\right): \delta 0.06\left(6 \mathrm{H}, \mathrm{s}, \mathrm{Si}-\left(\mathrm{CH}_{3}\right)_{2}\right), 0.75,0.84$, $0.93,1.67$ ( $6 \mathrm{H}$ for 0.84 , each $3 \mathrm{H}$ for others, s, 24, 25, 26, 27 and 30 $\left.\mathrm{CH}_{3}\right), 0.90(9 \mathrm{H}, \mathrm{s}, \mathrm{t}-\mathrm{Bu}), 2.13-2.20(1 \mathrm{H}, \mathrm{m}), 2.25-2.28(1 \mathrm{H}, \mathrm{m}), 3.01$ (1 H, m, H-19), 3.33, 3.65 (each $1 \mathrm{H}, \mathrm{d}, J=9.3 \mathrm{~Hz}, \mathrm{H}-23), 3.56(1 \mathrm{H}, \mathrm{m}$, $\mathrm{H}-3$ ), 4.59, 4.72 (each $1 \mathrm{H}, \mathrm{s}, \mathrm{H}-29$ ), 5.09, 5.15 (each $1 \mathrm{H}, \mathrm{d}, J=12.2 \mathrm{~Hz}$, $\left.\mathrm{CH}_{2}-\mathrm{Ph}\right), 7.32-7.35(5 \mathrm{H}, \mathrm{m}, \mathrm{H}-\mathrm{Ph})$.

3) Benzyl 3-oxo-23-t-butyldimethylsilyloxylup-20(29)-en-28oate (13): To a solution of $12(1.03 \mathrm{~g}, 1.5 \mathrm{mmol})$ in $\mathrm{CH}_{2} \mathrm{Cl}_{2}(30 \mathrm{~mL})$ was added PCC $(0.5 \mathrm{~g}, 2.3 \mathrm{mmol})$ at $0^{\circ} \mathrm{C}$. After being stirred at $0^{\circ} \mathrm{C}$ for $4 \mathrm{~h}$, the reaction mixture was warmed to room temperature and stirred overnight. The mixture was filtered and washed with $\mathrm{CH}_{2} \mathrm{Cl}_{2}(10$ $\mathrm{mL} \times 5)$. The filtrate was concentrated in vacuo to give a brown solid. Crystallization from ethanol gave 13 as a white solid $(0.91 \mathrm{~g}, 89 \%) . \mathrm{mp}$ 151-154 ${ }^{\circ} \mathrm{C} .{ }^{1} \mathrm{H}-\mathrm{NMR}\left(\mathrm{CDCl}_{3}, 300 \mathrm{MHz}\right): \delta 0.07\left(6 \mathrm{H}, \mathrm{s}, \mathrm{Si}-\left(\mathrm{CH}_{3}\right)_{2}\right), 0.80$, $0.83,0.86,0.96,1.68$ (each $3 \mathrm{H}, \mathrm{s}, 24,25,26,27$ and $30-\mathrm{CH}_{3}$ ), 0.87 (9 $\mathrm{H}, \mathrm{s}, \mathrm{t}-\mathrm{Bu}), 1.97(3 \mathrm{H}, \mathrm{s}, \mathrm{Ac}), 2.18-2.32(2 \mathrm{H}, \mathrm{m}), 2.37-2.42(2 \mathrm{H}, \mathrm{m})$, $3.04(1 \mathrm{H}, \mathrm{m}, \mathrm{H}-19), 3.28,3.56$ (each $1 \mathrm{H}, \mathrm{d}, \mathrm{J}=9.1 \mathrm{~Hz}, \mathrm{H}-23), 4.61,4.73$ (each $1 \mathrm{H}, \mathrm{d}, J=1.2 \mathrm{~Hz}, \mathrm{H}-29), 5.09,5.16$ (each $1 \mathrm{H}, \mathrm{d}, J=12.2 \mathrm{~Hz}, \mathrm{CH}_{2}-$ Ar), 7.35-7.38 (5 H, m, H-Ar); ESI-MS m/z: $675.5[\mathrm{M}+\mathrm{H}]^{+}, 697.5[\mathrm{M}$ $+\mathrm{Na}]^{+}, 714.5[\mathrm{M}+\mathrm{K}]^{+}$

4) Benzyl 3-oxo-23-hydroxy-lup-20(29)-en-28-oate (14): To a solution of $13(0.8 \mathrm{~g}, 1.2 \mathrm{mmol})$ in acetone $(30 \mathrm{~mL})$ were added $10 \%$ $\mathrm{HCl}(1 \mathrm{~mL})$. The reaction mixture was stirred at room temperature for $2 \mathrm{~h}$. At this point, the mixture was neutralized with $\mathrm{NaHCO}_{3}$ saturated solution, and then extracted with $\mathrm{CH}_{2} \mathrm{Cl}_{2}$, the $\mathrm{CH}_{2} \mathrm{Cl}_{2}$ layer was washed with brine, dried over anhydrous $\mathrm{Na}_{2} \mathrm{SO}_{4}$, filtered, and evaporated to dryness. The residue was purified by column chromatography (petroleum ether-EtOAc (5:1)) to give 14 as a white solid $(0.6 \mathrm{~g}, 90 \%)$. $\mathrm{mp} 175-178^{\circ} \mathrm{C}$. IR (film, $\mathrm{cm}^{-1}$ ) 3444, 3067, 2950, 2863, 1732, 1705, 1640, $1459,1381,1257,1121,1087,881,835,775,701 ;{ }^{1} \mathrm{H}-\mathrm{NMR}\left(\mathrm{CDCl}_{3}, 300\right.$ MHz): $\delta 0.74,0.88,0.92,0.95,1.61$ (each $3 \mathrm{H}, \mathrm{s}, 24,25,26,27$ and $30-$ $\left.\mathrm{CH}_{3}\right), 2.48-2.60(1 \mathrm{H}, \mathrm{m}), 2.95(1 \mathrm{H}, \mathrm{m}, \mathrm{H}-19), 3.33,3.56$ (each $1 \mathrm{H}, \mathrm{d}$, $J=11.3 \mathrm{~Hz}, \mathrm{H}-23$ ), 4.53, 4.66 (each $1 \mathrm{H}, \mathrm{s}, \mathrm{H}-29), 5.02,5.09$ (each $1 \mathrm{H}, \mathrm{d}$, $\left.J=11.1 \mathrm{~Hz}, \mathrm{CH}_{2}-\mathrm{Ar}\right), 7.23-7.31(5 \mathrm{H}, \mathrm{m}, \mathrm{H}-\mathrm{Ar}) ;$ ESI-MS $m / z: 561.3[\mathrm{M}$ $+\mathrm{H}]^{+}, 583.3[\mathrm{M}+\mathrm{Na}]^{+}, 599.0[\mathrm{M}+\mathrm{K}]^{+}$

5) 3,23-(1-methylethylidene acetal)-lup-20(29)-en-28-oic acid (16): To a solution of $2(1.00 \mathrm{~g}, 2.1 \mathrm{mmol})$ in anhydrous acetone $(30$ $\mathrm{mL})$ was added $\mathrm{TsOH}(0.1 \mathrm{~g})$ and DMP $(0.8 \mathrm{ml}, 7.6 \mathrm{mmol})$. The reaction mixture was refluxed for $4 \mathrm{~h}$. At this point, the mixture was evaporated and diluted with EtOAc $(30 \mathrm{~mL})$, the EtOAclayer was washed with brine, dried over anhydrous $\mathrm{Na}_{2} \mathrm{SO}_{4}$, filtered, and evaporated to dryness. The residue was purified by column chromatography (petroleum etherEtOAc (4:1)) to give 16 as a white solid $(0.94 \mathrm{~g}, 84 \%) .{ }^{1} \mathrm{H}-\mathrm{NMR}\left(\mathrm{CDCl}_{3}\right.$,
$300 \mathrm{MHz}$ ): $\delta 0.80,0.86,0.99,1.06,1.68$ (each $3 \mathrm{H}, \mathrm{s}, 24,25,26,27$ and $\left.30-\mathrm{CH}_{3}\right), 2.17 \sim 2.25(2 \mathrm{H}, \mathrm{m}), 2.99(1 \mathrm{H}, \mathrm{m}, \mathrm{H}-19), 3.43,3.52$ (each $1 \mathrm{H}$, d, J=10.5 Hz , H-23), 3.49 (1H, m, H-3), 4.61, 4.74 (each 1H, s, H-29); ESI-MS $m / z: 511.4[\mathrm{M}-\mathrm{H}]^{-}$

6) Ethyl 3,23-(1-methylethylidene acetal)-lup-20(29)-en-28oate (17): To a mixture of 16 (0.94 g, $1.8 \mathrm{mmol})$ and $\mathrm{K}_{2} \mathrm{CO}_{3}(1.00 \mathrm{~g}, 7.2$ $\mathrm{mmol})$ in DMF $(25 \mathrm{~mL})$ was added ethyl bromide $(0.27 \mathrm{ml}, 3.6 \mathrm{mmol})$ at room temperature for $12 \mathrm{~h}$. Then the mixture was diluted with EtOAc $(30 \mathrm{~mL})$, the EtOAc layer was washed with brine, dried over anhydrous $\mathrm{Na}_{2} \mathrm{SO}_{4}$, filtered, and evaporated to dryness. The residue was purified by column chromatography (petroleum ether-EtOAc (4:1)) to give 16 as a white solid $\left(0.89 \mathrm{~g}, 90 \%\right.$ ).IR (film, $\left.\mathrm{cm}^{-1}\right)$ 3469, 2988, 2847, 2866, 1719, $1447,1397,1253,1177,1154,1133,1114,1064,880 ;{ }^{1} \mathrm{H}-\mathrm{NMR}\left(\mathrm{CDCl}_{3}\right.$, $500 \mathrm{MHz}$ ): $\delta 0.86,0.90,0.95,1.02,1.68$ (each $3 \mathrm{H}, \mathrm{s}, 24,25,26,27$ and $\left.30-\mathrm{CH}_{3}\right), 2.17 \sim 2.25(2 \mathrm{H}, \mathrm{m}), 3.01(1 \mathrm{H}, \mathrm{m}, \mathrm{H}-19), 3.43,3.52$ (each $1 \mathrm{H}$, d, J=10.5 Hz , H-23), $3.49(1 \mathrm{H}, \mathrm{m}, \mathrm{H}-3), 4.13\left(2 \mathrm{H}, \mathrm{m}, \mathrm{COOCH}_{2} \mathrm{CH}_{3}\right)$, 4.61, 4.74 (each 1H, s, H-29).

7) 3,23-(1-methylethylidene acetal)-lup-20(29)-en-28-ol (18): To a solution of $17(0.89 \mathrm{~g}, 1.64 \mathrm{mmol})$ in dry THF $(25 \mathrm{~mL})$ was added $\mathrm{LiAlH}_{4}(0.32 \mathrm{~g}, 8 \mathrm{mmol})$. The reaction mixture was refluxed for $4 \mathrm{~h}$. At this point, the mixture was diluted with aqueous ether, and then extracted with $\mathrm{CH}_{2} \mathrm{Cl}_{2}$, the $\mathrm{CH}_{2} \mathrm{Cl}_{2}$ layer was washed with brine, dried over anhydrous $\mathrm{Na}_{2} \mathrm{SO}_{4}$, filtered, and evaporated to dryness. The residue was purified by column chromatography (petroleum etherEtOAc (2:1)) to give 18 as a white solid $(0.62 \mathrm{~g}, 76 \%)$.IR (film, $\mathrm{cm}^{-1}$ ) 3475, 2941, 2870, 1725, 1665, 1399, 1254, 1206, 1112, 1063, 1029, 853; ${ }^{1} \mathrm{H}-\mathrm{NMR}\left(\mathrm{CDCl}_{3}, 500 \mathrm{MHz}\right): \delta 0.87,0.97,1.02,1.44,1.68$ (each $3 \mathrm{H}, \mathrm{s}$, $24,25,26,27$ and $\left.30-\mathrm{CH}_{3}\right), 2.38(1 \mathrm{H}, \mathrm{m}, \mathrm{H}-19), 3.33,3.79$ (each $1 \mathrm{H}, \mathrm{d}$, $J=10.5 \mathrm{~Hz}, \mathrm{H}-28), 3.43,3.52$ (each $1 \mathrm{H}, \mathrm{d}, J=10.5 \mathrm{~Hz}, \mathrm{H}-23), 3.49(1 \mathrm{H}$, $\mathrm{m}, \mathrm{H}-3$ ), 4.58, 4.68 (each 1H, s, H-29).

8) General procedure for synthesis of compounds 15a-i and 19ai: Compound $14(0.1 \mathrm{~g}, 0.18 \mathrm{mmol})$ or $18(0.09 \mathrm{~g}, 0.18 \mathrm{mmol})$ was mixed with corresponding Compounds 10a-i (0.22 mmol), EDCI (93 mg, 0.6 $\mathrm{mmol}$ ) and DMAP (catalytic amount) in $15 \mathrm{~mL}$ of $\mathrm{CH}_{2} \mathrm{Cl}_{2}$ and stirred at room temperature for $8-16 \mathrm{~h}$. The reaction mixture was washed with water and saturated $\mathrm{NaCl}$ solution sequentially, dried over anhydrous $\mathrm{Na}_{2} \mathrm{SO}_{4}$, and concentrated in vacuo. The crude products were purified by column chromatography (petroleum ether-EtOAc (4:1)) to give the title compounds.

9) Benzyl 3-oxo-(23-O-(4-oxo-butyric acid-(3-phenylsulfonyl1,2,5-oxadiazole-2-oxide-4)-oxyethyl)-lup-20(29)-en-28-oate (15a): White solid, yield $48.2 \%$ mp. $50-53{ }^{\circ} \mathrm{C}$; IR (KBr) $v_{\max } 3435,2951,2869$, $1737,1455,1375,1334,1160,1074,962,736,621 \mathrm{~cm}^{-1} ;{ }^{1} \mathrm{H} \mathrm{NMR}\left(\mathrm{CDCl}_{3}\right.$, $300 \mathrm{MHz}$ ), $\delta$ (ppm) 0.80, 0.88, 0.92, 0.95, 1.60 (each $3 \mathrm{H}, \mathrm{s}, 24,25,26$, 27 and $\left.30-\mathrm{CH}_{3}\right), 2.39-2.50(1 \mathrm{H}, \mathrm{m}), 2.67\left(4 \mathrm{H}, \mathrm{m}, \mathrm{CO}\left(\mathrm{CH}_{2}\right)_{2} \mathrm{CO}\right), 3.02$ (1 H, m, H-19), 4.05 (2 H, s, H-23), 4.18, 4.47 (each $2 \mathrm{H}, \mathrm{t}, \mathrm{J}=6.0 \mathrm{~Hz}$, $\mathrm{O}\left(\mathrm{CH}_{2}\right)_{2} \mathrm{O}$ ), 4.59, 4.72 (each $\left.1 \mathrm{H}, \mathrm{s}, \mathrm{H}-29\right), 5.02,5.09$ (each $1 \mathrm{H}, \mathrm{d}, J=11.1$ $\left.\mathrm{Hz}, \mathrm{CH}_{2}-\mathrm{Ar}\right), 7.23-7.31(5 \mathrm{H}, \mathrm{m}, \mathrm{H}-\mathrm{Ar}), 7.59(2 \mathrm{H}, \mathrm{t}, J=7.8 \mathrm{~Hz}, \mathrm{H}-\mathrm{Ar})$, $7.73(2 \mathrm{H}, \mathrm{t}, J=6.9 \mathrm{~Hz}, \mathrm{H}-\mathrm{Ar}), 8.06(1 \mathrm{H}, \mathrm{d}, J=7.5 \mathrm{~Hz}, \mathrm{H}-\mathrm{Ar})$; ESI-MS $m / z$ : $929.4[\mathrm{M}+\mathrm{H}]^{+}$.

10) Benzyl 3-oxo-(23-O-(4-oxo-butyric acid-(3-phenylsulfonyl1,2,5-oxadiazole-2-oxide-4)-oxypropyl)-lup-20(29)-en-28-oate (15b): White solid, yield $47.6 \%$. mp. $46-49^{\circ} \mathrm{C}$; IR (KBr) $v_{\max } 3418,2951$, 2869, 1736, 1643, 1455, 1378, 1160, 736, $686 \mathrm{~cm}^{-1}$; ${ }^{1} \mathrm{H}$ NMR $\left(\mathrm{CDCl}_{3}, 300\right.$ $\mathrm{MHz}), \delta$ (ppm) 0.80, 0.88, 0.92, 0.95, 1.60 (each 3H, s, 24, 25, 26, 27 and $\left.30-\mathrm{CH}_{3}\right), 2.67\left(4 \mathrm{H}, \mathrm{m}, \mathrm{CO}\left(\mathrm{CH}_{2}\right)_{2} \mathrm{CO}\right), 3.02(1 \mathrm{H}, \mathrm{m}, \mathrm{H}-19), 4.05$, 4.11 (each $1 \mathrm{H}, \mathrm{s}, \mathrm{H}-23), 4.18\left(4 \mathrm{H}, \mathrm{m}, \mathrm{O}\left(\mathrm{CH}_{2}\right)_{3} \mathrm{O}\right), 4.59,4.71$ (each $1 \mathrm{H}, \mathrm{s}$, H-29), 5.02, 5.09 (each $\left.1 \mathrm{H}, \mathrm{d}, J=11.1 \mathrm{~Hz}, \mathrm{CH}_{2}-\mathrm{Ar}\right), 7.26-7.31(5 \mathrm{H}, \mathrm{m}$, $\mathrm{H}-\mathrm{Ar}), 7.53(2 \mathrm{H}, \mathrm{t}, J=7.8 \mathrm{~Hz}, \mathrm{H}-\mathrm{Ar}), 7.65(2 \mathrm{H}, \mathrm{t}, J=6.9 \mathrm{~Hz}, \mathrm{H}-\mathrm{Ar}), 8.07$ $(1 \mathrm{H}, \mathrm{d}, \mathrm{J}=7.5 \mathrm{~Hz}, \mathrm{H}-\mathrm{Ar})$; MS(ESI) $m / z: 943.4[\mathrm{M}+\mathrm{H}]^{+}$ 
Citation: Liu J, Sun F, Zhang H, Cai H, Yao H, et al. (2015) Synthesis and Biological Evaluation of Novel Furozan-Based Nitric Oxide-Releasing Derivatives of 23-Hydroxy Betulinic Acid and 3-oxo-23-hydroxybetulinic acid as Potential Anti-Tumor Agents. Med chem 5: 028-036. doi:10.4172/2161-0444.1000239

11) Benzyl 3-oxo-(23-O-(4-oxo-butyric acid-(3-phenylsulfonyl1,2,5-oxadiazole-2-oxide-4)- oxybutyl)-lup-20(29)-en-28-oate (15c): White solid, yield $47.2 \%$. mp. $42-45^{\circ} \mathrm{C}$; IR (KBr) $v_{\max } 3420,2951,2869$, $1736,1644,1455,1331,1160,736,621 \mathrm{~cm}^{-1} ;{ }^{1} \mathrm{H}$ 坚 $\mathrm{NMR}\left(\mathrm{CDCl}_{3}, 300\right.$ $\mathrm{MHz}$ ), $\delta$ (ppm) $0.79,0.88,0.91,0.96,1.60$ (each $3 \mathrm{H}, \mathrm{s}, 24,25,26,27$ and $\left.30-\mathrm{CH}_{3}\right), 2.39-2.50(2 \mathrm{H}, \mathrm{m}), 2.65\left(4 \mathrm{H}, \mathrm{m}, \mathrm{CO}\left(\mathrm{CH}_{2}\right)_{2} \mathrm{CO}\right), 3.01(1 \mathrm{H}, \mathrm{m}$, $\mathrm{H}-19), 4.05$ (2H, s, H-23), 4.18, 4.47 (each $\left.2 \mathrm{H}, \mathrm{t}, \mathrm{J}=6.0 \mathrm{~Hz}, \mathrm{O}\left(\mathrm{CH}_{2}\right)_{4} \mathrm{O}\right)$, 4.59, 4.71 (each $1 \mathrm{H}, \mathrm{s}, \mathrm{H}-29), 5.06,5.09$ (each $1 \mathrm{H}, \mathrm{d}, J=11.1 \mathrm{~Hz}, \mathrm{CH}_{2}-$ Ar), $7.27-7.35(5 \mathrm{H}, \mathrm{m}, \mathrm{H}-\mathrm{Ar}), 7.59(2 \mathrm{H}, \mathrm{t}, J=7.8 \mathrm{~Hz}, \mathrm{H}-\mathrm{Ar}), 7.65(2 \mathrm{H}$, t, $J=6.9 \mathrm{~Hz}, \mathrm{H}-\mathrm{Ar}), 8.07(1 \mathrm{H}, \mathrm{d}, J=7.5 \mathrm{~Hz}, \mathrm{H}-\mathrm{Ar})$; MS(ESI) $\mathrm{m} / z: 957.4$ $[\mathrm{M}+\mathrm{H}]^{+}$

12) Benzyl 3-oxo-(23-0-(5-oxo-pentanoic acid-(3phenylsulfonyl-1,2,5-oxadiazole-2-oxide-4)-oxyethyl)-lup-20(29)en-28-oate (15d): White solid, yield $48.1 \%$. mp. $55-58^{\circ} \mathrm{C}$; IR (KBr) $v_{\max } 3420,2952,2869,1736,1643,1455,1160,736,686 \mathrm{~cm}^{-1} ;{ }^{1} \mathrm{H}$ $\mathrm{NMR}\left(\mathrm{CDCl}_{3}, 300 \mathrm{MHz}\right), \delta(\mathrm{ppm})$ 0.79, 0.88, 0.91, 0.96, 1.60 (each $3 \mathrm{H}$, s, 24, 25, 26, 27 and $\left.30-\mathrm{CH}_{3}\right), 2.38\left(4 \mathrm{H}, \mathrm{m}, \mathrm{CO}\left(\mathrm{CH}_{2}\right)_{3} \mathrm{CO}\right), 3.00(1 \mathrm{H}, \mathrm{m}$, $\mathrm{H}-19), 4.01(2 \mathrm{H}, \mathrm{s}, \mathrm{H}-23), 4.38\left(4 \mathrm{H}, \mathrm{t}, J=5.4 \mathrm{~Hz}, \mathrm{O}\left(\mathrm{CH}_{2}\right)_{2} \mathrm{O}\right), 4.60,4.72$ (each $1 \mathrm{H}, \mathrm{s}, \mathrm{H}-29$ ), 5.07, 5.10 (each $1 \mathrm{H}, \mathrm{d}, \mathrm{J}=11.1 \mathrm{~Hz}, \mathrm{CH}_{2}-\mathrm{Ar}$ ), 7.27$7.35(5 \mathrm{H}, \mathrm{m}, \mathrm{H}-\mathrm{Ar}), 7.59(2 \mathrm{H}, \mathrm{t}, J=7.8 \mathrm{~Hz}, \mathrm{H}-\mathrm{Ar}), 7.65(2 \mathrm{H}, \mathrm{t}, J=6.9 \mathrm{~Hz}$, H-Ar), 8.07 (1H, d, J=7.5 Hz, H-Ar); MS(ESI) $m / z: 942.4[\mathrm{M}+\mathrm{H}]^{+}$.

13) Benzyl 3-oxo-(23-O-(5-oxo-pentanoic acid-(3phenylsulfonyl-1,2,5-oxadiazole-2-oxide-4)-oxypropyl)-lup-20(29)en-28-oate (15e): White solid, yield 45.9\%. mp. 60-63 ${ }^{\circ} \mathrm{C}$; IR ( $\left.\mathrm{KBr}\right)$ $v_{\max } 3417,2951,2869,1736,1643,1455,1331,1160,736,686 \mathrm{~cm}^{-1} ;{ }^{1} \mathrm{H}$ $\operatorname{NMR}\left(\mathrm{CDCl}_{3}, 300 \mathrm{MHz}\right), \delta(\mathrm{ppm})$ 0.79, 0.88, 0.91, 0.96, 1.60 (each $3 \mathrm{H}$, $\mathrm{s}, 24,25,26,27$ and $\left.30-\mathrm{CH}_{3}\right), 2.40\left(4 \mathrm{H}, \mathrm{m}, \mathrm{CO}\left(\mathrm{CH}_{2}\right)_{3} \mathrm{CO}\right), 3.00(1 \mathrm{H}, \mathrm{m}$, $\mathrm{H}-19), 4.02(2 \mathrm{H}, \mathrm{s}, \mathrm{H}-23), 4.38\left(4 \mathrm{H}, \mathrm{t}, J=5.4 \mathrm{~Hz}, \mathrm{O}\left(\mathrm{CH}_{2}\right)_{3} \mathrm{O}\right), 4.60,4.72$ (each $1 \mathrm{H}, \mathrm{s}, \mathrm{H}-29), 5.07,5.10$ (each $1 \mathrm{H}, \mathrm{d}, J=11.1 \mathrm{~Hz}, \mathrm{CH}_{2}-\mathrm{Ar}$ ), 7.27$7.35(5 \mathrm{H}, \mathrm{m}, \mathrm{H}-\mathrm{Ar}), 7.59(2 \mathrm{H}, \mathrm{t}, J=7.8 \mathrm{~Hz}, \mathrm{H}-\mathrm{Ar}), 7.65(2 \mathrm{H}, \mathrm{t}, J=6.9$ $\mathrm{Hz}, \mathrm{H}-\mathrm{Ar}), 8.07(1 \mathrm{H}, \mathrm{d}, J=7.5 \mathrm{~Hz}, \mathrm{H}-\mathrm{Ar})$; MS(ESI) $m / z: 957.4[\mathrm{M}+\mathrm{H}]^{+}$

14) Benzyl 3-oxo-(23-O-(5-oxo-pentanoic acid-(3phenylsulfonyl-1,2,5-oxadiazole-2-oxide-4)-oxybutyl)-lup-20(29)en-28-oate (15f): White solid, yield $46.2 \%$. mp. 59-62 ${ }^{\circ} \mathrm{C}$; IR ( $\mathrm{KBr}$ ) $v_{\max } 3420,2951,2869,1736,1455,1378,1160,1018,736,621 \mathrm{~cm}^{-1} ;{ }^{1} \mathrm{H}$ $\operatorname{mMR}\left(\mathrm{CDCl}_{3}, 300 \mathrm{MHz}\right), \delta(\mathrm{ppm}) 0.80,0.88,0.92,0.95,1.60$ (each $3 \mathrm{H}$, $\mathrm{s}, 24,25,26,27$ and $\left.30-\mathrm{CH}_{3}\right), 2.42\left(4 \mathrm{H}, \mathrm{m}, \mathrm{CO}\left(\mathrm{CH}_{2}\right)_{3} \mathrm{CO}\right), 3.02(1 \mathrm{H}, \mathrm{m}$, $\mathrm{H}-19), 4.05(2 \mathrm{H}, \mathrm{s}, \mathrm{H}-23), 4.38\left(4 \mathrm{H}, \mathrm{t}, J=6.0 \mathrm{~Hz}, \mathrm{O}\left(\mathrm{CH}_{2}\right)_{4} \mathrm{O}\right), 4.59,4.72$ (each $1 \mathrm{H}, \mathrm{s}, \mathrm{H}-29), 5.02,5.09$ (each $1 \mathrm{H}, \mathrm{d}, J=11.1 \mathrm{~Hz}, \mathrm{CH}_{2}-\mathrm{Ar}$ ), 7.23$7.31(5 \mathrm{H}, \mathrm{m}, \mathrm{H}-\mathrm{Ar}), 7.59(2 \mathrm{H}, \mathrm{t}, J=7.8 \mathrm{~Hz}, \mathrm{H}-\mathrm{Ar}), 7.73(2 \mathrm{H}, \mathrm{t}, J=6.9$ $\mathrm{Hz}, \mathrm{H}-\mathrm{Ar}), 8.06(1 \mathrm{H}, \mathrm{d}, J=7.5 \mathrm{~Hz}, \mathrm{H}-\mathrm{Ar})$; ESI-MS m/z: $971.4[\mathrm{M}+\mathrm{H}]^{+}$

15) Benzyl 3-oxo-(23-O-(2-formyl benzoic acid-(3phenylsulfonyl-1,2,5-oxadiazole-2-oxide-4)- oxyethyl)-lup-20(29)en-28-oate (15 g): White solid, yield $45.0 \%$. mp. 54-57 ${ }^{\circ} \mathrm{C}$; IR (KBr) $v_{\max } 3440,2924,2854,1726,1617,1551,1450,1170,740,597 \mathrm{~cm}^{-1}{ }^{1} \mathrm{H}$ $\mathrm{NMR}\left(\mathrm{CDCl}_{3}, 500 \mathrm{MHz}\right), \delta(\mathrm{ppm}) 0.79,0.88,0.92,0.95,1.61$ (each $3 \mathrm{H}$, s, 24, 25, 26, 27 and 30- $\left.\mathrm{CH}_{3}\right), 2.39-2.50(1 \mathrm{H}, \mathrm{m}), 3.01(1 \mathrm{H}, \mathrm{m}, \mathrm{H}-19)$, $4.24(2 \mathrm{H}, \mathrm{m}, \mathrm{H}-23), 4.58,4.71$ (each $1 \mathrm{H}, \mathrm{s}, \mathrm{H}-29), 4.73(4 \mathrm{H}, \mathrm{t}, J=6.0 \mathrm{~Hz}$, $\left.\mathrm{O}\left(\mathrm{CH}_{2}\right)_{2} \mathrm{O}\right), 5.02,5.09$ (each $1 \mathrm{H}, \mathrm{d}, \mathrm{J}=11.1 \mathrm{~Hz}, \mathrm{CH}_{2}-\mathrm{Ar}$ ), 7.23-7.31 (5 $\mathrm{H}, \mathrm{m}, \mathrm{H}-\mathrm{Ar}), 7.55(2 \mathrm{H}, \mathrm{t}, J=5.0 \mathrm{~Hz}, \mathrm{H}-\mathrm{Ar}), 7.59(2 \mathrm{H}, \mathrm{t}, J=7.8 \mathrm{~Hz}, \mathrm{H}-\mathrm{Ar})$, $7.71(2 \mathrm{H}, \mathrm{t}, J=5.0 \mathrm{~Hz}, \mathrm{H}-\mathrm{Ar}), 7.73(2 \mathrm{H}, \mathrm{t}, J=6.9 \mathrm{~Hz}, \mathrm{H}-\mathrm{Ar}), 8.06(1 \mathrm{H}, \mathrm{d}$, $J=7.5 \mathrm{~Hz}, \mathrm{H}-\mathrm{Ar})$; ESI-MS $m / z: 977.4[\mathrm{M}+\mathrm{H}]^{+}$

16) Benzyl 3-oxo-(23-O-(2-formyl benzoic acid-(3phenylsulfonyl-1,2,5-oxadiazole-2-oxide-4)- oxypropyl)-lup20(29)-en-28-oate (15h): White solid, yield 44.9\%. mp. 50-53 ${ }^{\circ} \mathrm{C}$; IR $(\mathrm{KBr}) v_{\text {max }} 3445,2925,2854,1726,1617,1552,1450,1270,1170,740$, 698, $597 \mathrm{~cm}^{-1}{ }^{1} \mathrm{H} \mathrm{NMR}\left(\mathrm{CDCl}_{3}, 500 \mathrm{MHz}\right), \delta$ (ppm) 0.79, 0.88, 0.92, $0.95,1.61$ (each $3 \mathrm{H}, \mathrm{s}, 24,25,26,27$ and $\left.30-\mathrm{CH}_{3}\right), 2.39-2.50(1 \mathrm{H}, \mathrm{m})$, $3.01(1 \mathrm{H}, \mathrm{m}, \mathrm{H}-19), 4.15$ (2 H, m, H-23), 4.52, 4.57 (each 1H, t, $J=6.0$ $\mathrm{Hz}, \mathrm{O}\left(\mathrm{CH}_{2}\right)_{3} \mathrm{O}$ ), 4.59, 4.71 (each $\left.1 \mathrm{H}, \mathrm{s}, \mathrm{H}-29\right), 5.02,5.09$ (each $1 \mathrm{H}, \mathrm{d}$,
$J=11.1 \mathrm{~Hz}, \mathrm{CH}_{2}$-Ar), 7.23-7.31 (5 H, m, H-Ar), $7.55(2 \mathrm{H}, \mathrm{t}, J=7.5 \mathrm{~Hz}$, $\mathrm{H}-\mathrm{Ar}), 7.59$ (2H, t, $J=7.8 \mathrm{~Hz}, \mathrm{H}-\mathrm{Ar}), 7.71(1 \mathrm{H}, \mathrm{t}, J=5.0 \mathrm{~Hz}, \mathrm{H}-\mathrm{Ar}), 7.73$ $(2 \mathrm{H}, \mathrm{t}, J=6.9 \mathrm{~Hz}, \mathrm{H}-\mathrm{Ar}), 8.06(2 \mathrm{H}, \mathrm{d}, J=7.5 \mathrm{~Hz}, \mathrm{H}-\mathrm{Ar})$; ESI-MS $m / z$ : $991.4[\mathrm{M}+\mathrm{H}]^{+}$

17) Benzyl 3-oxo-(23-0-(2-formyl benzoic acid-(3phenylsulfonyl-1,2,5-oxadiazole-2-oxide-4)-oxybutyl)-lup-20(29)en-28-oate (15i): White solid, yield $45.9 \%$. mp. $49-52^{\circ} \mathrm{C}$; IR (KBr) $v_{\max }$ $3445,2925,2853,1726,1617,1551,1450,1270,1170,740,698,597$, $556 \mathrm{~cm}^{-1}{ }^{1} \mathrm{H} \mathrm{NMR}\left(\mathrm{CDCl}_{3}, 500 \mathrm{MHz}\right), \delta(\mathrm{ppm}) 0.79,0.88,0.92,0.95$, 1.61 (each $3 \mathrm{H}, \mathrm{s}, 24,25,26,27$ and $\left.30-\mathrm{CH}_{3}\right), 2.39-2.50(1 \mathrm{H}, \mathrm{m}), 3.01$ (1 H, m, H-19), 4.27 (2 H, s, H-23), 4.52, 4.57 (each $1 \mathrm{H}, \mathrm{t}, J=6.0 \mathrm{~Hz}$, $\mathrm{O}\left(\mathrm{CH}_{2}\right)_{3} \mathrm{O}$ ), 4.59, 4.71 (each 1H, s, H-29), 5.02, 5.09 (each $1 \mathrm{H}, \mathrm{d}, J=11.1$ $\mathrm{Hz}, \mathrm{CH}_{2}-\mathrm{Ar}$ ), 7.23-7.31 (5 H, m, H-Ar), 7.55 (2H, t, J=7.5 Hz, H-Ar), $7.59(2 \mathrm{H}, \mathrm{t}, J=7.8 \mathrm{~Hz}, \mathrm{H}-\mathrm{Ar}), 7.71(1 \mathrm{H}, \mathrm{t}, J=5.0 \mathrm{~Hz}, \mathrm{H}-\mathrm{Ar}), 7.73(2 \mathrm{H}, \mathrm{t}$, $J=6.9 \mathrm{~Hz}, \mathrm{H}-\mathrm{Ar}), 8.06(2 \mathrm{H}, \mathrm{d}, J=7.5 \mathrm{~Hz}, \mathrm{H}-\mathrm{Ar})$; ESI-MS m/z: $1005.4[\mathrm{M}$ $+\mathrm{H}]^{+}$

18) 3, 23-(1-methylethylidene acetal)-lup-20(29)-en-28-O-(4oxo-butyric acid-(3-phenylsulfonyl-1,2,5-oxadiazole-2-oxide-4)oxyethyl)-ate (19a): White solid, yield $51.4 \% .{ }^{1} \mathrm{H} \mathrm{NMR}\left(\mathrm{CDCl}_{3}, 500\right.$ $\mathrm{MHz}$ ), $\delta$ (ppm) 0.81, 0.88, 0.91, 0.96, 1.60 (each 3H, s, 24, 25, 26, 27 and $\left.30-\mathrm{CH}_{3}\right), 2.47(1 \mathrm{H}, \mathrm{m}, \mathrm{H}-19), 2.69\left(4 \mathrm{H}, \mathrm{m}, \mathrm{CO}\left(\mathrm{CH}_{2}\right)_{2} \mathrm{CO}\right), 3.43,3.52$ (each $1 \mathrm{H}, \mathrm{d}, J=10.5 \mathrm{~Hz}, \mathrm{H}-23), 3.49(1 \mathrm{H}, \mathrm{m}, \mathrm{H}-3), 3.88,4.30$ (each $1 \mathrm{H}$, d, $J=10 \mathrm{~Hz}, \mathrm{H}-28$ ), 4.50, 4.68 (each $\left.2 \mathrm{H}, \mathrm{d}, J=7.5 \mathrm{~Hz}, \mathrm{O}\left(\mathrm{CH}_{2}\right)_{2} \mathrm{O}\right), 4.58$, 4.69 (each $1 \mathrm{H}, \mathrm{s}, \mathrm{H}-29), 7.62(2 \mathrm{H}, \mathrm{t}, J=7.5 \mathrm{~Hz}, \mathrm{H}-\mathrm{Ar}), 7.74(1 \mathrm{H}, \mathrm{t}, J=7.5$ $\mathrm{Hz}, \mathrm{H}-\mathrm{Ar}), 8.07$ (2H, d, J=7.5 Hz, H-Ar)

19) 3, 23-(1-methylethylidene acetal)-lup-20(29)-en-28-O-(4oxo-butyric acid-(3-phenylsulfonyl-1,2,5-oxadiazole-2-oxide-4)oxypropyl)-ate (19b): White solid, yield $48.9 \% .{ }^{1} \mathrm{H} \mathrm{NMR}\left(\mathrm{CDCl}_{3}, 500\right.$ $\mathrm{MHz}), \delta$ (ppm) 0.81, 0.88, 0.91, 0.96, 1.61 (each 3H, s, 24, 25, 26, 27 and $\left.30-\mathrm{CH}_{3}\right), 2.43(1 \mathrm{H}, \mathrm{m}, \mathrm{H}-19), 2.65\left(4 \mathrm{H}, \mathrm{m}, \mathrm{CO}\left(\mathrm{CH}_{2}\right)_{2} \mathrm{CO}\right), 3.43,3.52$ (each $1 \mathrm{H}, \mathrm{d}, J=10.5 \mathrm{~Hz}, \mathrm{H}-23), 3.49(1 \mathrm{H}, \mathrm{m}, \mathrm{H}-3), 3.85,4.30$ (each $1 \mathrm{H}$, d, $J=10.5 \mathrm{~Hz}, \mathrm{H}-28), 4.31,4.51$ (each $\left.2 \mathrm{H}, \mathrm{t}, J=6 \mathrm{~Hz}, \mathrm{O}\left(\mathrm{CH}_{2}\right)_{3} \mathrm{O}\right), 4.58$, 4.69 (each $1 \mathrm{H}, \mathrm{s}, \mathrm{H}-29), 7.62(2 \mathrm{H}, \mathrm{t}, J=7.5 \mathrm{~Hz}, \mathrm{H}-\mathrm{Ar}), 7.74(1 \mathrm{H}, \mathrm{t}, J=7.5$ $\mathrm{Hz}, \mathrm{H}-\mathrm{Ar}), 8.07$ (2H, d, J=7.5 Hz, H-Ar)

20) 3, 23-(1-methylethylidene acetal)-lup-20(29)-en-28-O-(4oxo-butyric acid-(3-phenylsulfonyl-1,2,5-oxadiazole-2-oxide-4)oxybutyl)-ate (19c): White solid, yield $50.5 \% .{ }^{1} \mathrm{H} \mathrm{NMR}\left(\mathrm{CDCl}_{3}, 300\right.$ $\mathrm{MHz}), \delta$ (ppm) 0.81, 0.88, 0.91, 0.96, 1.61 (each 3H, s, 24, 25, 26, 27 and $\left.30-\mathrm{CH}_{3}\right), 2.43(1 \mathrm{H}, \mathrm{m}, \mathrm{H}-19), 2.66\left(4 \mathrm{H}, \mathrm{m}, \mathrm{CO}\left(\mathrm{CH}_{2}\right)_{2} \mathrm{CO}\right), 3.43,3.51$ (each $1 \mathrm{H}, \mathrm{d}, J=10.5 \mathrm{~Hz}, \mathrm{H}-23), 3.49(1 \mathrm{H}, \mathrm{m}, \mathrm{H}-3), 3.85,4.30$ (each $1 \mathrm{H}$, d, J=11.1 Hz, H-28), 4.18, 4.47 (each $\left.2 \mathrm{H}, \mathrm{t}, \mathrm{J}=6 \mathrm{~Hz}, \mathrm{O}\left(\mathrm{CH}_{2}\right)_{4} \mathrm{O}\right), 4.58$, 4.69 (each $1 \mathrm{H}, \mathrm{s}, \mathrm{H}-29), 7.62(2 \mathrm{H}, \mathrm{t}, \mathrm{J}=7.2 \mathrm{~Hz}, \mathrm{H}-\mathrm{Ar}), 7.74(1 \mathrm{H}, \mathrm{t}, \mathrm{J}=6.3$ $\mathrm{Hz}, \mathrm{H}-\mathrm{Ar}), 8.07$ (2H, d, J=7.5 Hz, H-Ar)

21)3,23-(1-methylethylidene acetal)-lup-20(29)-en-28-O-(5oxo-pentanoic acid-(3-phenylsulfonyl-1,2,5-oxadiazole-2-oxide-4)oxyethyl)-ate (19d): White solid, yield $53.2 \% .{ }^{1} \mathrm{H} \mathrm{NMR}\left(\mathrm{CDCl}_{3}, 500\right.$ $\mathrm{MHz}$ ), $\delta$ (ppm) 0.81, 0.88, 0.96, 1.02, 1.60 (each 3H, s, 24, 25, 26, 27 and $\left.30-\mathrm{CH}_{3}\right), 2.41(1 \mathrm{H}, \mathrm{m}, \mathrm{H}-19), 2.43\left(4 \mathrm{H}, \mathrm{m}, \mathrm{CO}\left(\mathrm{CH}_{2}\right)_{3} \mathrm{CO}\right), 3.43,3.52$ (each $1 \mathrm{H}, \mathrm{d}, J=10.5 \mathrm{~Hz}, \mathrm{H}-23), 3.49(1 \mathrm{H}, \mathrm{m}, \mathrm{H}-3), 3.86,4.30$ (each $1 \mathrm{H}$, d, $J=10 \mathrm{~Hz}, \mathrm{H}-28), 4.51,4.64\left(\right.$ each $\left.2 \mathrm{H}, \mathrm{t}, J=4.5 \mathrm{~Hz}, \mathrm{O}\left(\mathrm{CH}_{2}\right)_{2} \mathrm{O}\right), 4.58$, 4.69 (each 1H, s, H-29), $7.62(2 \mathrm{H}, \mathrm{t}, J=7.5 \mathrm{~Hz}, \mathrm{H}-\mathrm{Ar}), 7.74(1 \mathrm{H}, \mathrm{t}, J=7.5$ $\mathrm{Hz}, \mathrm{H}-\mathrm{Ar}), 8.07$ (2H, d, J=7.5 Hz, H-Ar)

22) 3,23-(1-methylethylidene acetal)-lup-20(29)-en-28-O-(5oxo-pentanoic acid-(3-phenylsulfonyl-1,2,5-oxadiazole-2-oxide-4)oxypropyl)-ate (19e): White solid, yield $49.7 \% .{ }^{1} \mathrm{H} \mathrm{NMR}\left(\mathrm{CDCl}_{3}, 500\right.$ $\mathrm{MHz}), \delta$ (ppm) 0.81, 0.88, 0.96, 1.02, 1.61 (each $3 \mathrm{H}, \mathrm{s}, 24,25,26,27$ and 30- $\left.\mathrm{CH}_{3}\right), 2.41(1 \mathrm{H}, \mathrm{m}, \mathrm{H}-19), 2.43\left(4 \mathrm{H}, \mathrm{m}, \mathrm{CO}\left(\mathrm{CH}_{2}\right)_{3} \mathrm{CO}\right), 3.43,3.52$ (each $1 \mathrm{H}, \mathrm{d}, J=10.5 \mathrm{~Hz}, \mathrm{H}-23), 3.49(1 \mathrm{H}, \mathrm{m}, \mathrm{H}-3), 3.85,4.30$ (each $1 \mathrm{H}$, d, J=10 Hz, H-28), 4.51, $4.64\left(\right.$ each $\left.2 \mathrm{H}, \mathrm{t}, \mathrm{J}=4.5 \mathrm{~Hz}, \mathrm{O}\left(\mathrm{CH}_{2}\right)_{3} \mathrm{O}\right), 4.58$, 
Citation: Liu J, Sun F, Zhang H, Cai H, Yao H, et al. (2015) Synthesis and Biological Evaluation of Novel Furozan-Based Nitric Oxide-Releasing Derivatives of 23-Hydroxy Betulinic Acid and 3-oxo-23-hydroxybetulinic acid as Potential Anti-Tumor Agents. Med chem 5: 028-036. doi:10.4172/2161-0444.1000239

4.69 (each $1 \mathrm{H}, \mathrm{s}, \mathrm{H}-29), 7.62(2 \mathrm{H}, \mathrm{t}, \mathrm{J}=7.5 \mathrm{~Hz}, \mathrm{H}-\mathrm{Ar}), 7.74(1 \mathrm{H}, \mathrm{t}, \mathrm{J}=7.5$ $\mathrm{Hz}, \mathrm{H}-\mathrm{Ar}), 8.07(2 \mathrm{H}, \mathrm{d}, \mathrm{J}=7.5 \mathrm{~Hz}, \mathrm{H}-\mathrm{Ar})$

23) 3,23-(1-methylethylidene acetal)-lup-20(29)-en-28-O-(5oxo-pentanoic acid-(3-phenylsulfonyl-1,2,5-oxadiazole-2-oxide-4)oxybutyl)-ate (19f): White solid, yield $51.2 \% .{ }^{1} \mathrm{H} \mathrm{NMR}\left(\mathrm{CDCl}_{3}, 300\right.$ $\mathrm{MHz}$ ), $\delta$ (ppm) $0.81,0.88,0.91,0.96,1.61$ (each $3 \mathrm{H}, \mathrm{s}, 24,25,26,27$ and $\left.30-\mathrm{CH}_{3}\right), 2.41(1 \mathrm{H}, \mathrm{m}, \mathrm{H}-19), 2.43\left(4 \mathrm{H}, \mathrm{m}, \mathrm{CO}\left(\mathrm{CH}_{2}\right)_{3} \mathrm{CO}\right), 3.43,3.52$ (each $1 \mathrm{H}, \mathrm{d}, J=10.5 \mathrm{~Hz}, \mathrm{H}-23), 3.49(1 \mathrm{H}, \mathrm{m}, \mathrm{H}-3), 3.85,4.30$ (each $1 \mathrm{H}$, d, J=11.1 Hz, H-28), 4.50, 4.64 (each $\left.2 \mathrm{H}, \mathrm{t}, \mathrm{J}=4.5 \mathrm{~Hz}, \mathrm{O}\left(\mathrm{CH}_{2}\right)_{4} \mathrm{O}\right), 4.58$, 4.69 (each $1 \mathrm{H}, \mathrm{s}, \mathrm{H}-29), 7.62(2 \mathrm{H}, \mathrm{t}, \mathrm{J}=7.2 \mathrm{~Hz}, \mathrm{H}-\mathrm{Ar}), 7.74(1 \mathrm{H}, \mathrm{t}, \mathrm{J}=6.3$ $\mathrm{Hz}, \mathrm{H}-\mathrm{Ar}), 8.07$ (2H, d, J=7.5 Hz, H-Ar)

24) 3,23-(1-methylethylidene acetal)-lup-20(29)-en-28-O-(2formyl benzoic acid-(3-phenylsulfonyl-1,2,5-oxadiazole-2-oxide-4)oxyethyl)-ate (19 g): White solid, yield $53.8 \% .{ }^{1} \mathrm{H} \mathrm{NMR}\left(\mathrm{CDCl}_{3}, 500\right.$ $\mathrm{MHz}$ ), $\delta$ (ppm) 0.82, 0.87, 0.98, 1.02, 1.60 (each $3 \mathrm{H}, \mathrm{s}, 24,25,26,27$ and $\left.30-\mathrm{CH}_{3}\right), 2.50$ (1H, m, H-19), 3.43, 3.52 (each $1 \mathrm{H}, \mathrm{d}, J=10.5 \mathrm{~Hz}, \mathrm{H}-23$ ), $3.49(1 \mathrm{H}, \mathrm{m}, \mathrm{H}-3), 4.06,4.46$ (each $1 \mathrm{H}, \mathrm{d}, J=10.5 \mathrm{~Hz}, \mathrm{H}-28), 4.59,4.70$ (each $1 \mathrm{H}, \mathrm{s}, \mathrm{H}-29), 4.74\left(4 \mathrm{H}, \mathrm{m}, \mathrm{O}\left(\mathrm{CH}_{2}\right)_{2} \mathrm{O}\right), 7.46(2 \mathrm{H}, \mathrm{t}, J=7.5 \mathrm{~Hz}$, $\mathrm{H}-\mathrm{Ar}), 7.58(2 \mathrm{H}, \mathrm{t}, J=4.5 \mathrm{~Hz}, \mathrm{H}-\mathrm{Ar}), 7.64(1 \mathrm{H}, \mathrm{t}, J=7.5 \mathrm{~Hz}, \mathrm{H}-\mathrm{Ar}), 7.72$ $(1 \mathrm{H}, \mathrm{t}, J=4.5 \mathrm{~Hz}, \mathrm{H}-\mathrm{Ar}), 7.82(1 \mathrm{H}, \mathrm{t}, J=4.5 \mathrm{~Hz}, \mathrm{H}-\mathrm{Ar}), 8.07(2 \mathrm{H}, \mathrm{d}, J=7.5$ $\mathrm{Hz}, \mathrm{H}-\mathrm{Ar})$

25) 3, 23-(1-methylethylidene acetal)-lup-20(29)-en-28-O-(2formyl benzoic acid-(3-phenylsulfonyl-1,2,5-oxadiazole-2-oxide-4)oxypropyl)-ate (19h): White solid, yield $48.7 \% .{ }^{1} \mathrm{H} \mathrm{NMR}\left(\mathrm{CDCl}_{3}, 500\right.$ $\mathrm{MHz}$ ), $\delta$ (ppm) 0.82, 0.87, 0.98, 1.02, 1.60 (each $3 \mathrm{H}, \mathrm{s}, 24,25,26,27$ and $\left.30-\mathrm{CH}_{3}\right), 2.51(1 \mathrm{H}, \mathrm{m}, \mathrm{H}-19), 3.43,3.52$ (each $1 \mathrm{H}, \mathrm{d}, J=10.5 \mathrm{~Hz}, \mathrm{H}-23$ ), $3.49(1 \mathrm{H}, \mathrm{m}, \mathrm{H}-3), 4.07,4.47$ (each $1 \mathrm{H}, \mathrm{d}, J=10.5 \mathrm{~Hz}, \mathrm{H}-28), 4.60,4.70$ (each $1 \mathrm{H}, \mathrm{s}, \mathrm{H}-29), 4.74\left(4 \mathrm{H}, \mathrm{m}, \mathrm{O}\left(\mathrm{CH}_{2}\right)_{3} \mathrm{O}\right), 7.46(2 \mathrm{H}, \mathrm{t}, J=7.5 \mathrm{~Hz}$, $\mathrm{H}-\mathrm{Ar}), 7.58(2 \mathrm{H}, \mathrm{t}, J=4.5 \mathrm{~Hz}, \mathrm{H}-\mathrm{Ar}), 7.64(1 \mathrm{H}, \mathrm{t}, J=7.5 \mathrm{~Hz}, \mathrm{H}-\mathrm{Ar}), 7.72$ $(1 \mathrm{H}, \mathrm{t}, J=4.5 \mathrm{~Hz}, \mathrm{H}-\mathrm{Ar}), 7.82(1 \mathrm{H}, \mathrm{t}, J=4.5 \mathrm{~Hz}, \mathrm{H}-\mathrm{Ar}), 8.07(2 \mathrm{H}, \mathrm{d}, J=7.5$ $\mathrm{Hz}, \mathrm{H}-\mathrm{Ar})$

26) 3, 23-(1-methylethylidene acetal)-lup-20(29)-en-28-O-(2formyl benzoic acid-(3-phenylsulfonyl-1,2,5-oxadiazole-2-oxide-4)oxybutyl)-ate (19i): White solid, yield $46.5 \% .{ }^{1} \mathrm{H} \mathrm{NMR}\left(\mathrm{CDCl}_{3}, 300\right.$ $\mathrm{MHz}$ ), $\delta$ (ppm) 0.82, 0.86, 0.98, 1.02, 1.60 (each $3 \mathrm{H}, \mathrm{s}, 24,25,26,27$ and $\left.30-\mathrm{CH}_{3}\right), 2.48(1 \mathrm{H}, \mathrm{m}, \mathrm{H}-19), 3.43,3.52$ (each $1 \mathrm{H}, \mathrm{d}, J=10.5 \mathrm{~Hz}, \mathrm{H}-23$ ), 3.49 (1H, m, H-3), 4.06, 4.46 (each $1 \mathrm{H}, \mathrm{d}, J=10.8 \mathrm{~Hz}, \mathrm{H}-28), 4.59,4.70$ (each $1 \mathrm{H}, \mathrm{s}, \mathrm{H}-29), 4.74\left(4 \mathrm{H}, \mathrm{m}, \mathrm{O}\left(\mathrm{CH}_{2}\right)_{4} \mathrm{O}\right), 7.46(2 \mathrm{H}, \mathrm{t}, J=7.5 \mathrm{~Hz}$, $\mathrm{H}-\mathrm{Ar}), 7.58(2 \mathrm{H}, \mathrm{t}, J=4.5 \mathrm{~Hz}, \mathrm{H}-\mathrm{Ar}), 7.64(1 \mathrm{H}, \mathrm{t}, J=7.5 \mathrm{~Hz}, \mathrm{H}-\mathrm{Ar}), 7.71$ $(1 \mathrm{H}, \mathrm{t}, J=4.5 \mathrm{~Hz}, \mathrm{H}-\mathrm{Ar}), 7.82(1 \mathrm{H}, \mathrm{t}, J=4.5 \mathrm{~Hz}, \mathrm{H}-\mathrm{Ar}), 8.07(2 \mathrm{H}, \mathrm{d}, J=7.5$ $\mathrm{Hz}, \mathrm{H}-\mathrm{Ar})$

27) General procedure for synthesis of compounds 20a-i: To a solution of $19 \mathrm{a}-\mathbf{i}(2 \mathrm{mmol})$ in THF $(10 \mathrm{~mL})$ were added $10 \% \mathrm{HCl}(10$ $\mathrm{mL}$ ). The reaction mixture was stirred at room temperature for $2 \mathrm{~h}$. At this point, the mixture was neutralized with $\mathrm{NaHCO}_{3}$ saturated solution, and then extracted with $\mathrm{CH}_{2} \mathrm{Cl}_{2}$, the $\mathrm{CH}_{2} \mathrm{Cl}_{2}$ layer was washed with brine, dried over anhydrous $\mathrm{Na}_{2} \mathrm{SO}_{4}$, filtered, and evaporated to dryness. The residue was purified by column chromatography (dichloromethane-methanol, (30:1)) to give the title compounds.

28) 3,23-dihydroxy-lup-20(29)-en-28-O-(4-oxo-butyric acid(3-phenylsulfonyl-1,2,5-oxadiazole-2-oxide-4)-oxyethyl)-ate (20a): White solid, yield $75.1 \%$. mp. $54-57^{\circ} \mathrm{C}$; IR (KBr) v $3420,2926,2854$, $1733,1618,1553,1283,739,685,598 \mathrm{~cm}^{-1} ;{ }^{1} \mathrm{H} \mathrm{NMR}\left(\mathrm{CDCl}_{3}, 500 \mathrm{MHz}\right)$, $\delta$ (ppm) 0.81, 0.88, 0.91, 0.96, 1.60 (each 3H, s, 24, 25, 26, 27 and 30$\left.\mathrm{CH}_{3}\right), 2.47(1 \mathrm{H}, \mathrm{m}, \mathrm{H}-19), 2.69\left(4 \mathrm{H}, \mathrm{m}, \mathrm{CO}\left(\mathrm{CH}_{2}\right)_{2} \mathrm{CO}\right), 3.41,3.70$ (each $1 \mathrm{H}, \mathrm{d}, J=10 \mathrm{~Hz}, \mathrm{H}-23), 3.60(1 \mathrm{H}, \mathrm{m}, \mathrm{H}-3), 3.88,4.30$ (each $1 \mathrm{H}, \mathrm{d}, J=10$ $\mathrm{Hz}, \mathrm{H}-28), 4.50,4.68$ (each $\left.2 \mathrm{H}, \mathrm{d}, J=7.5 \mathrm{~Hz}, \mathrm{O}\left(\mathrm{CH}_{2}\right)_{2} \mathrm{O}\right), 4.58,4.69$ (each $1 \mathrm{H}, \mathrm{s}, \mathrm{H}-29), 7.62(2 \mathrm{H}, \mathrm{t}, J=7.5 \mathrm{~Hz}, \mathrm{H}-\mathrm{Ar}), 7.74(1 \mathrm{H}, \mathrm{t}, J=7.5 \mathrm{~Hz}$, H-Ar), 8.07 (2H, d, J=7.5 Hz, H-Ar); MS(ESI) $m / z: 844.4\left[\mathrm{M}+\mathrm{NH}_{4}\right]^{+}$.
29) 3,23-dihydroxy-lup-20(29)-en-28-O-(4-oxo-butyric acid-(3phenylsulfonyl-1,2,5-oxadiazole-2-oxide-4)-oxypropyl)-ate (20b): White solid, yield $72.3 \%$. mp. 52-55 ${ }^{\circ} \mathrm{C}$; IR (KBr) $v_{\max } 3420,2925,2854$, $1734,1618,1553,1284,740,685,598 \mathrm{~cm}^{-1} ;{ }^{1} \mathrm{H} \mathrm{NMR}\left(\mathrm{CDCl}_{3}, 300 \mathrm{MHz}\right)$, $\delta$ (ppm) 0.81, 0.88, 0.91, 0.96, 1.61 (each 3H, s, 24, 25, 26, 27 and 30$\left.\mathrm{CH}_{3}\right), 2.43(1 \mathrm{H}, \mathrm{m}, \mathrm{H}-19), 2.65\left(4 \mathrm{H}, \mathrm{m}, \mathrm{CO}\left(\mathrm{CH}_{2}\right)_{2} \mathrm{CO}\right), 3.39,3.69$ (each $1 \mathrm{H}, \mathrm{d}, J=8.4 \mathrm{~Hz}, \mathrm{H}-23), 3.60$ (1H, m, H-3), 3.85, 4.30 (each $1 \mathrm{H}, \mathrm{d}, J=10.5$ $\mathrm{Hz}, \mathrm{H}-28$ ), 4.31, 4.51 (each $2 \mathrm{H}, \mathrm{t}, J=6 \mathrm{~Hz}, \mathrm{O}\left(\mathrm{CH}_{2}\right)_{3} \mathrm{O}$ ), 4.58, 4.69 (each $1 \mathrm{H}, \mathrm{s}, \mathrm{H}-29), 7.62(2 \mathrm{H}, \mathrm{t}, J=7.5 \mathrm{~Hz}, \mathrm{H}-\mathrm{Ar}), 7.74(1 \mathrm{H}, \mathrm{t}, J=7.5 \mathrm{~Hz}, \mathrm{H}-\mathrm{Ar})$, $8.07(2 \mathrm{H}, \mathrm{d}, J=7.5 \mathrm{~Hz}, \mathrm{H}-\mathrm{Ar})$; MS(ESI) $m / z: 858.4\left[\mathrm{M}+\mathrm{NH}_{4}\right]^{+}$

30) 3,23-dihydroxy-lup-20(29)-en-28-O-(4-oxo-butyric acid(3-phenylsulfonyl-1,2,5-oxadiazole-2-oxide-4)-oxybutyl)-ate (20c): White solid, yield $70.3 \%$. mp. $48-51^{\circ} \mathrm{C}$; IR ( $\left.\mathrm{KBr}\right) v_{\max } 3420,2926,2854$, $1734,1618,1553,1283,740,685,598 \mathrm{~cm}^{-1}$; ${ }^{1} \mathrm{H} \mathrm{NMR}\left(\mathrm{CDCl}_{3}, 300 \mathrm{MHz}\right)$, $\delta(\mathrm{ppm}) 0.81,0.88,0.91,0.96,1.61$ (each $3 \mathrm{H}, \mathrm{s}, 24,25,26,27$ and $30-$ $\left.\mathrm{CH}_{3}\right), 2.43(1 \mathrm{H}, \mathrm{m}, \mathrm{H}-19), 2.66\left(4 \mathrm{H}, \mathrm{m}, \mathrm{CO}\left(\mathrm{CH}_{2}\right)_{2} \mathrm{CO}\right), 3.40,3.69$ (each $1 \mathrm{H}, \mathrm{d}, \mathrm{J}=8.4 \mathrm{~Hz}, \mathrm{H}-23), 3.60(1 \mathrm{H}, \mathrm{m}, \mathrm{H}-3), 3.85,4.30$ (each $1 \mathrm{H}, \mathrm{d}, \mathrm{J}=11.1$ $\mathrm{Hz}, \mathrm{H}-28$ ) , 4.18, 4.47 (each $2 \mathrm{H}, \mathrm{t}, \mathrm{J}=6 \mathrm{~Hz}, \mathrm{O}\left(\mathrm{CH}_{2}\right)_{4} \mathrm{O}$ ), 4.58, 4.69 (each $1 \mathrm{H}, \mathrm{s}, \mathrm{H}-29), 7.62(2 \mathrm{H}, \mathrm{t}, \mathrm{J}=7.2 \mathrm{~Hz}, \mathrm{H}-\mathrm{Ar}), 7.74(1 \mathrm{H}, \mathrm{t}, \mathrm{J}=6.3 \mathrm{~Hz}, \mathrm{H}-\mathrm{Ar})$, $8.07(2 \mathrm{H}, \mathrm{d}, \mathrm{J}=7.5 \mathrm{~Hz}, \mathrm{H}-\mathrm{Ar}) ; \mathrm{MS}(\mathrm{ESI}) \mathrm{m} / \mathrm{z}: 872.4\left[\mathrm{M}+\mathrm{NH}_{4}\right]^{+}$

31) 3,23-dihydroxy-lup-20(29)-en-28-O-(5-oxo-pentanoic acid(3-phenylsulfonyl-1,2,5-oxadiazole-2-oxide-4)-oxyethyl)-ate (20d): White solid, yield $74.9 \%$. mp. $73-76^{\circ} \mathrm{C}$; IR (KBr) $v_{\max } 3420,2925,2854$, $1733,1618,1553,1285,739,685,598 \mathrm{~cm}^{-1} ;{ }^{1} \mathrm{H} \mathrm{NMR}\left(\mathrm{CDCl}_{3}, 500 \mathrm{MHz}\right)$, $\delta$ (ppm) 0.81, 0.88, 0.96, 1.02, 1.60 (each $3 \mathrm{H}, \mathrm{s}, 24,25,26,27$ and $30-$ $\left.\mathrm{CH}_{3}\right), 2.41(1 \mathrm{H}, \mathrm{m}, \mathrm{H}-19), 2.43\left(4 \mathrm{H}, \mathrm{m}, \mathrm{CO}\left(\mathrm{CH}_{2}\right)_{3} \mathrm{CO}\right), 3.42,3.71$ (each $1 \mathrm{H}, \mathrm{d}, J=10 \mathrm{~Hz}, \mathrm{H}-23), 3.62(1 \mathrm{H}, \mathrm{m}, \mathrm{H}-3), 3.86,4.30$ (each $1 \mathrm{H}, \mathrm{d}, J=10$ $\mathrm{Hz}, \mathrm{H}-28), 4.51,4.64$ (each $\left.2 \mathrm{H}, \mathrm{t}, J=4.5 \mathrm{~Hz}, \mathrm{O}\left(\mathrm{CH}_{2}\right)_{2} \mathrm{O}\right), 4.58,4.69$ (each $1 \mathrm{H}, \mathrm{s}, \mathrm{H}-29), 7.62(2 \mathrm{H}, \mathrm{t}, J=7.5 \mathrm{~Hz}, \mathrm{H}-\mathrm{Ar}), 7.74(1 \mathrm{H}, \mathrm{t}, J=7.5 \mathrm{~Hz}, \mathrm{H}-\mathrm{Ar})$, $8.07(2 \mathrm{H}, \mathrm{d}, J=7.5 \mathrm{~Hz}, \mathrm{H}-\mathrm{Ar})$; MS(ESI) $m / z: 858.4\left[\mathrm{M}+\mathrm{NH}_{4}\right]^{+}$.

32) 3,23-dihydroxy-lup-20(29)-en-28-O-(5-oxo-pentanoic acid-(3-phenylsulfonyl-1,2,5-oxadiazole-2-oxide-4)-oxypropyl)-ate (20e): White solid, yield $70.3 \%$. mp. $63-66^{\circ} \mathrm{C}$; IR (KBr) $v_{\max } 3420,2926$, 2854, 1734, 1618, 1553, 1283, 740, 685, $598 \mathrm{~cm}^{-1} ;{ }^{1} \mathrm{H}$ NMR( $\left(\mathrm{CDCl}_{3}, 500\right.$ $\mathrm{MHz}), \delta(\mathrm{ppm}) 0.81,0.88,0.96,1.02,1.61$ (each $3 \mathrm{H}, \mathrm{s}, 24,25,26,27$ and $\left.30-\mathrm{CH}_{3}\right), 2.41(1 \mathrm{H}, \mathrm{m}, \mathrm{H}-19), 2.43\left(4 \mathrm{H}, \mathrm{m}, \mathrm{CO}\left(\mathrm{CH}_{2}\right)_{3} \mathrm{CO}\right), 3.40,3.69$ (each $1 \mathrm{H}, \mathrm{d}, \mathrm{J}=10 \mathrm{~Hz}, \mathrm{H}-23), 3.60(1 \mathrm{H}, \mathrm{m}, \mathrm{H}-3), 3.85,4.30$ (each $1 \mathrm{H}, \mathrm{d}$, $\mathrm{J}=10 \mathrm{~Hz}, \mathrm{H}-28), 4.51,4.64\left(\right.$ each $\left.2 \mathrm{H}, \mathrm{t}, \mathrm{J}=4.5 \mathrm{~Hz}, \mathrm{O}\left(\mathrm{CH}_{2}\right)_{3} \mathrm{O}\right), 4.58,4.69$ (each 1H, s, H-29), $7.62(2 \mathrm{H}, \mathrm{t}, \mathrm{J}=7.5 \mathrm{~Hz}, \mathrm{H}-\mathrm{Ar}), 7.74(1 \mathrm{H}, \mathrm{t}, \mathrm{J}=7.5 \mathrm{~Hz}$, $\mathrm{H}-\mathrm{Ar}), 8.07(2 \mathrm{H}, \mathrm{d}, \mathrm{J}=7.5 \mathrm{~Hz}, \mathrm{H}-\mathrm{Ar})$; MS(ESI) m/z: $872.4\left[\mathrm{M}+\mathrm{NH}_{4}\right]^{+}$

33) 3,23-dihydroxy-lup-20(29)-en-28-O-(5-oxo-pentanoic acid(3-phenylsulfonyl-1,2,5-oxadiazole-2-oxide-4)-oxybutyl)-ate (20f): White solid, yield $67.8 \%$. mp. 61-64 ${ }^{\circ} \mathrm{C}$; IR (KBr) v $v_{\max } 3420,2926,2854$, $1734,1618,1553,1283,740,685,598 \mathrm{~cm}^{-1}$; ${ }^{1} \mathrm{H} \mathrm{NMR}\left(\mathrm{CDCl}_{3}, 300 \mathrm{MHz}\right)$, $\delta$ (ppm) 0.81, 0.88, 0.91, 0.96, 1.61 (each 3H, s, 24, 25, 26, 27 and 30$\left.\mathrm{CH}_{3}\right), 2.41(1 \mathrm{H}, \mathrm{m}, \mathrm{H}-19), 2.43\left(4 \mathrm{H}, \mathrm{m}, \mathrm{CO}\left(\mathrm{CH}_{2}\right)_{3} \mathrm{CO}\right), 3.40,3.69$ (each $1 \mathrm{H}, \mathrm{d}, \mathrm{J}=8.4 \mathrm{~Hz}, \mathrm{H}-23), 3.60(1 \mathrm{H}, \mathrm{m}, \mathrm{H}-3), 3.85,4.30$ (each $1 \mathrm{H}, \mathrm{d}, \mathrm{J}=11.1$ $\mathrm{Hz}, \mathrm{H}-28), 4.50,4.64$ (each $\left.2 \mathrm{H}, \mathrm{t}, \mathrm{J}=4.5 \mathrm{~Hz}, \mathrm{O}\left(\mathrm{CH}_{2}\right)_{4} \mathrm{O}\right), 4.58,4.69$ (each $1 \mathrm{H}, \mathrm{s}, \mathrm{H}-29), 7.62(2 \mathrm{H}, \mathrm{t}, \mathrm{J}=7.2 \mathrm{~Hz}, \mathrm{H}-\mathrm{Ar}), 7.74(1 \mathrm{H}, \mathrm{t}, \mathrm{J}=6.3 \mathrm{~Hz}, \mathrm{H}-\mathrm{Ar})$, $8.07(2 \mathrm{H}, \mathrm{d}, \mathrm{J}=7.5 \mathrm{~Hz}, \mathrm{H}-\mathrm{Ar})$; MS(ESI) m/z: $886.4\left[\mathrm{M}+\mathrm{NH}_{4}\right]^{+}$

34) 3,23-dihydroxy-lup-20(29)-en-28-O-(2-formyl benzoic acid(3-phenylsulfonyl-1,2,5-oxadiazole-2-oxide-4)-oxyethyl)-ate (20g): White solid, yield $65.1 \%$ mp. $95-98^{\circ} \mathrm{C}$; IR (KBr) v $v_{\max } 3440,2924$, 2854, 1726, 1617, 1551, 1450, 1170, 740, $597 \mathrm{~cm}^{-1} ;{ }^{1} \mathrm{H} \mathrm{NMR}_{\max }\left(\mathrm{CDCl}_{3}, 500\right.$ $\mathrm{MHz}$ ), $\delta$ (ppm) 0.82, 0.87, 0.98, 1.02, 1.60 (each $3 \mathrm{H}, \mathrm{s}, 24,25,26,27$ and $\left.30-\mathrm{CH}_{3}\right), 2.50(1 \mathrm{H}, \mathrm{m}, \mathrm{H}-19), 3.42,3.71$ (each $1 \mathrm{H}, \mathrm{d}, J=9.5 \mathrm{~Hz}, \mathrm{H}-23$ ), $3.62(1 \mathrm{H}, \mathrm{m}, \mathrm{H}-3), 4.06,4.46$ (each $1 \mathrm{H}, \mathrm{d}, J=10.5 \mathrm{~Hz}, \mathrm{H}-28), 4.59,4.70$ (each $1 \mathrm{H}, \mathrm{s}, \mathrm{H}-29), 4.74\left(4 \mathrm{H}, \mathrm{m}, \mathrm{O}\left(\mathrm{CH}_{2}\right)_{2} \mathrm{O}\right), 7.46(2 \mathrm{H}, \mathrm{t}, J=7.5 \mathrm{~Hz}$, $\mathrm{H}-\mathrm{Ar}), 7.58(2 \mathrm{H}, \mathrm{t}, J=4.5 \mathrm{~Hz}, \mathrm{H}-\mathrm{Ar}), 7.64(1 \mathrm{H}, \mathrm{t}, J=7.5 \mathrm{~Hz}, \mathrm{H}-\mathrm{Ar}), 7.72$ 
Citation: Liu J, Sun F, Zhang H, Cai H, Yao H, et al. (2015) Synthesis and Biological Evaluation of Novel Furozan-Based Nitric Oxide-Releasing Derivatives of 23-Hydroxy Betulinic Acid and 3-oxo-23-hydroxybetulinic acid as Potential Anti-Tumor Agents. Med chem 5: 028-036. doi:10.4172/2161-0444.1000239

$(1 \mathrm{H}, \mathrm{t}, J=4.5 \mathrm{~Hz}, \mathrm{H}-\mathrm{Ar}), 7.82(1 \mathrm{H}, \mathrm{t}, J=4.5 \mathrm{~Hz}, \mathrm{H}-\mathrm{Ar}), 8.07(2 \mathrm{H}, \mathrm{d}, J=7.5$ $\mathrm{Hz}, \mathrm{H}-\mathrm{Ar}) ; \mathrm{MS}(\mathrm{ESI}) \mathrm{m} / z: 892.4\left[\mathrm{M}+\mathrm{NH}_{4}\right]^{+}$

35) 3,23-dihydroxy-lup-20(29)-en-28-O-(2-formyl benzoic acid-(3-phenylsulfonyl-1,2,5-oxadiazole-2-oxide-4)-oxypropyl)-ate (20h): White solid, yield 68.3\%.mp. $78-81^{\circ} \mathrm{C}$; IR (KBr) $v_{\max } 3439,2924$, 2854, 1726, 1618, 1551, 1450, 1170, 740, $597 \mathrm{~cm}^{-1}$; ${ }^{1} \mathrm{H}$ NMR $\left(\mathrm{CDCl}_{3}, 500\right.$ $\mathrm{MHz}), \delta(\mathrm{ppm}) 0.82,0.87,0.98,1.02,1.60$ (each $3 \mathrm{H}, \mathrm{s}, 24,25,26,27$ and $\left.30-\mathrm{CH}_{3}\right), 2.51(1 \mathrm{H}, \mathrm{m}, \mathrm{H}-19), 3.41,3.70$ (each $1 \mathrm{H}, \mathrm{d}, J=9.5 \mathrm{~Hz}, \mathrm{H}-23$ ), $3.62(1 \mathrm{H}, \mathrm{m}, \mathrm{H}-3), 4.07,4.47$ (each $1 \mathrm{H}, \mathrm{d}, J=10.5 \mathrm{~Hz}, \mathrm{H}-28), 4.60,4.70$ (each $1 \mathrm{H}, \mathrm{s}, \mathrm{H}-29), 4.74\left(4 \mathrm{H}, \mathrm{m}, \mathrm{O}\left(\mathrm{CH}_{2}\right)_{3} \mathrm{O}\right), 7.46(2 \mathrm{H}, \mathrm{t}, J=7.5 \mathrm{~Hz}$, $\mathrm{H}-\mathrm{Ar}), 7.58(2 \mathrm{H}, \mathrm{t}, J=4.5 \mathrm{~Hz}, \mathrm{H}-\mathrm{Ar}), 7.64(1 \mathrm{H}, \mathrm{t}, J=7.5 \mathrm{~Hz}, \mathrm{H}-\mathrm{Ar}), 7.72$ $(1 \mathrm{H}, \mathrm{t}, J=4.5 \mathrm{~Hz}, \mathrm{H}-\mathrm{Ar}), 7.82(1 \mathrm{H}, \mathrm{t}, J=4.5 \mathrm{~Hz}, \mathrm{H}-\mathrm{Ar}), 8.07(2 \mathrm{H}, \mathrm{d}, J=7.5$ $\mathrm{Hz}, \mathrm{H}-\mathrm{Ar}$ ); MS(ESI) $m / z: 906.4\left[\mathrm{M}+\mathrm{NH}_{4}\right]^{+}$

36) 3,23-dihydroxy-lup-20(29)-en-28-O-(2-formyl benzoic acid(3-phenylsulfonyl-1,2,5-oxadiazole-2-oxide-4)-oxybutyl)-ate (20i): White solid, yield $64.5 \%$ mp. $75-78^{\circ} \mathrm{C}$; IR (KBr) v $v_{\max } 3440,2925$, 2854, 1726, 1618, 1551, 1450, 1170, 740, $597 \mathrm{~cm}^{-1} ;{ }^{1} \mathrm{H}$ NMR( $\left(\mathrm{CDCl}_{3}, 300\right.$ $\mathrm{MHz}), \delta(\mathrm{ppm}) 0.82,0.86,0.98,1.02,1.60$ (each $3 \mathrm{H}, \mathrm{s}, 24,25,26,27$ and $\left.30-\mathrm{CH}_{3}\right), 2.48(1 \mathrm{H}, \mathrm{m}, \mathrm{H}-19), 3.40,3.70$ (each $1 \mathrm{H}, \mathrm{d}, J=7.5 \mathrm{~Hz}, \mathrm{H}-23$ ), $3.61(1 \mathrm{H}, \mathrm{m}, \mathrm{H}-3), 4.06,4.46$ (each $1 \mathrm{H}, \mathrm{d}, J=10.8 \mathrm{~Hz}, \mathrm{H}-28), 4.59,4.70$ (each $1 \mathrm{H}, \mathrm{s}, \mathrm{H}-29), 4.74\left(4 \mathrm{H}, \mathrm{m}, \mathrm{O}\left(\mathrm{CH}_{2}\right)_{4} \mathrm{O}\right), 7.46(2 \mathrm{H}, \mathrm{t}, J=7.5 \mathrm{~Hz}$, $\mathrm{H}-\mathrm{Ar}), 7.58(2 \mathrm{H}, \mathrm{t}, J=4.5 \mathrm{~Hz}, \mathrm{H}-\mathrm{Ar}), 7.64(1 \mathrm{H}, \mathrm{t}, J=7.5 \mathrm{~Hz}, \mathrm{H}-\mathrm{Ar}), 7.71$ $(1 \mathrm{H}, \mathrm{t}, J=4.5 \mathrm{~Hz}, \mathrm{H}-\mathrm{Ar}), 7.82(1 \mathrm{H}, \mathrm{t}, J=4.5 \mathrm{~Hz}, \mathrm{H}-\mathrm{Ar}), 8.07$ (2H, d, $J=7.5$ $\mathrm{Hz}, \mathrm{H}-\mathrm{Ar}$ ); $\mathrm{MS}$ (ESI) $m / z: 920.4\left[\mathrm{M}+\mathrm{NH}_{4}\right]^{+}$

\section{NO-releasing test}

The levels of nitrate/nitrite formed from individual compounds were determined by the colorimetric assay using the nitrate/nitrite colorimetric assay kit (Nanjing Jiancheng Bioengineering Institute) according to the manufacturer's instructions. $10 \mu \mathrm{mol} / \mathrm{L}$ of each compound in phosphate buffer solution (PBS) containing 2\% dimethyl sulfoxide and $5.0 \mathrm{mM} \mathrm{L}$-cysteine at $\mathrm{pH} 7.4$ was incubated at $37^{\circ} \mathrm{C}$ for $10-150 \mathrm{~min}$ and were sampled at $10 \mathrm{~min}, 30 \mathrm{~min}, 60 \mathrm{~min}, 80 \mathrm{~min}, 100$ min, $120 \mathrm{~min}$ and $150 \mathrm{~min}$. The collected samples $(2 \mathrm{~mL})$ were mixed with $0.5 \mathrm{ml}$ of Griess reagent and incubated at $37^{\circ} \mathrm{C}$ for $10 \mathrm{~min}$, followed by measuring at $540 \mathrm{~nm}$. The different concentrations of nitrite were used as standards to calculate the concentrations of NO formed by individual compounds.

\section{MTT assay}

The MTT assay was employed in vitro for anti-proliferative activity assay, which was performed in 96-well plates. Four different cell lines were used: B16 (mice melanoma), A549 (human lung carcinoma), BEL7402 (human hepatoma), K562 (human leukemic cell). Test cells at the $\log$ phase of their growth cycle $(5 \times 104 \mathrm{cell} / \mathrm{mL})$ were added to each well $(100 \mu \mathrm{L} /$ well $)$, then treated in four replicates at various concentrations of the samples $(0.39-100 \mu \mathrm{g} / \mathrm{mL})$, and incubated for $24 \mathrm{~h}$ at $37^{\circ} \mathrm{C}$ in a humidified atmosphere of $5 \% \mathrm{CO}_{2}$. After $72 \mathrm{~h}, 20 \mu \mathrm{L}$ of MTT solution $(5 \mathrm{mg} / \mathrm{mL})$ per well was added to each cultured medium, which was incubated for further $4 \mathrm{~h}$. Then, DMSO was added to each well (150 $\mu \mathrm{L} /$ well). After $10 \mathrm{~min}$ at room temperature, the OD of each well was measured on a Microplate Reader (BIO-RAD instruments Inc NO.550) at a wavelength of $490 \mathrm{~nm}$. In these experiments, the negative reference was $0.1 \%$ DMSO, and Taxol was used as the positive reference.

\section{Results and Discussion}

\section{Chemistry}

As shown in (Scheme 1), the substituted furoxans were prepared in five steps sequence. The starting material benzenethiol (4) was converted to 2-(phenylthio) acetic acid (6) by treatment with chloroacetic acid (5) in 97\% yield. Then, compound 6 was oxidized by $30 \% \mathrm{H}_{2} \mathrm{O}_{2}$ aqueous solution to generate 2-(phenylsulfonyl) acetic acid (7). Furthermore, fuming $\mathrm{HNO}_{3}$ was added to obtain diphenylsulfonylfuroxan (8). Subsequently, 8 was then converted to various monophenylsulfonylfuroxans $9 \mathrm{a}-\mathrm{c}$ by treatment with the corresponding diol. Finally, anhydrides were added and furoxan-based NO donors 10a-i were obtained.

The general procedure for the synthesis of derivatives $15 \mathrm{a}-\mathrm{i}$ was described in (Scheme 2). For the synthetic experiments, the starting material 23-hydroxybetulinic acid (2) was isolated from the root of Pulsatilla chinensis. It was mixed with benzyl bromide and potassium carbonate in DMF at room temperature for $2 \mathrm{~h}$ to give benzyl ester 11 in $92 \%$ yield. Silyl ether 12 was prepared in high yield using the regular method, and then an oxidation reaction was followed on C-3 position with PCC afforded ketone 13. Deprotection of 13 with $10 \% \mathrm{HCl}$ in acetone at room temperature produced benzyl 3-oxo-23-

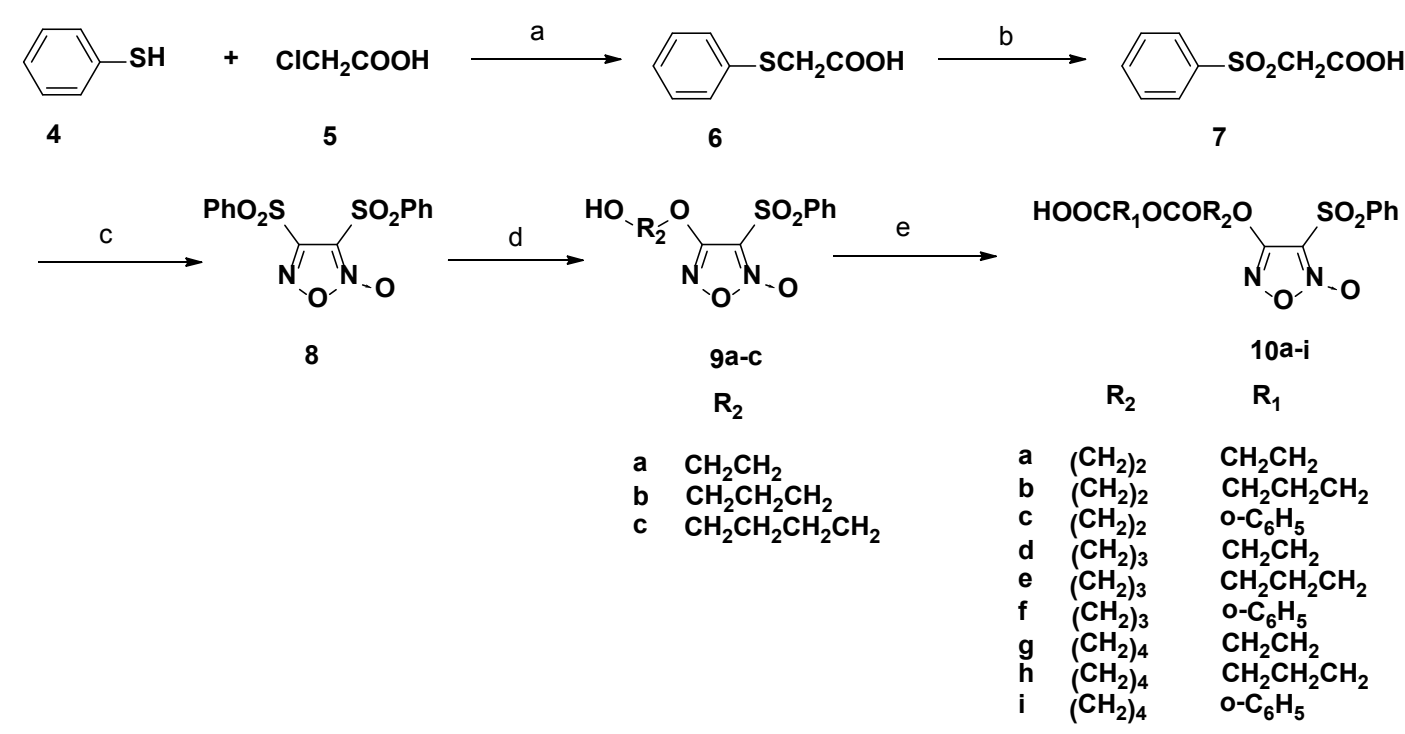

Scheme 1: General method for the synthesis of 10a-i. Reagents and conditions: (a) $\mathrm{NaOH}(\mathrm{aq}), 140{ }^{\circ} \mathrm{C}, 2 \mathrm{~h} ;(\mathrm{b}) 30 \% \mathrm{H}_{2} \mathrm{O}_{2}, \mathrm{AcOH}, \mathrm{rt}, 3 \mathrm{~h}$; (c) fuming $\mathrm{HNO}{ }_{3}, 90{ }^{\circ} \mathrm{C}, 4 \mathrm{~h}$; (d) diol, THF, 30\% NaOH, rt, 4-8h; (e) anhydrides, pyridine, rt, 6-12h. 


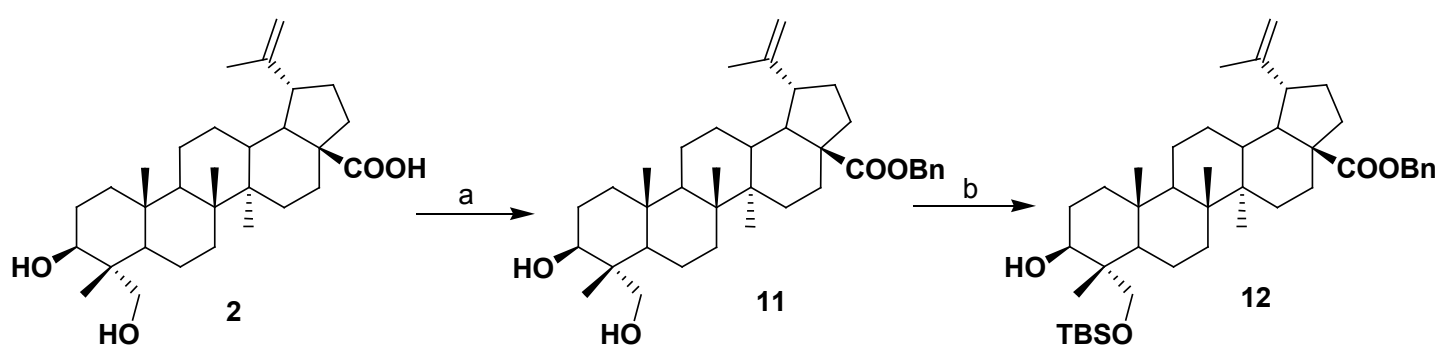

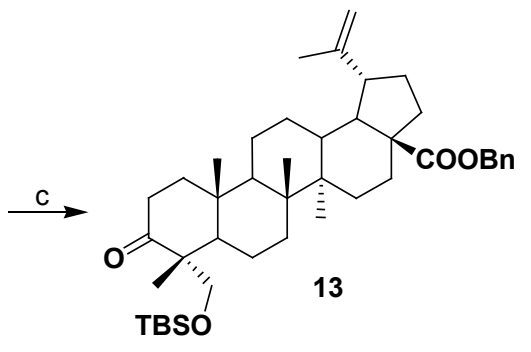

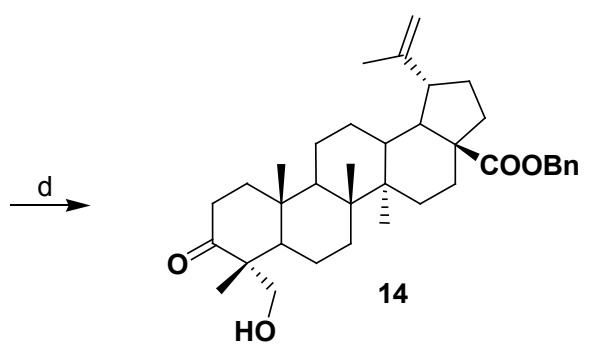

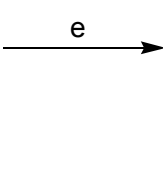

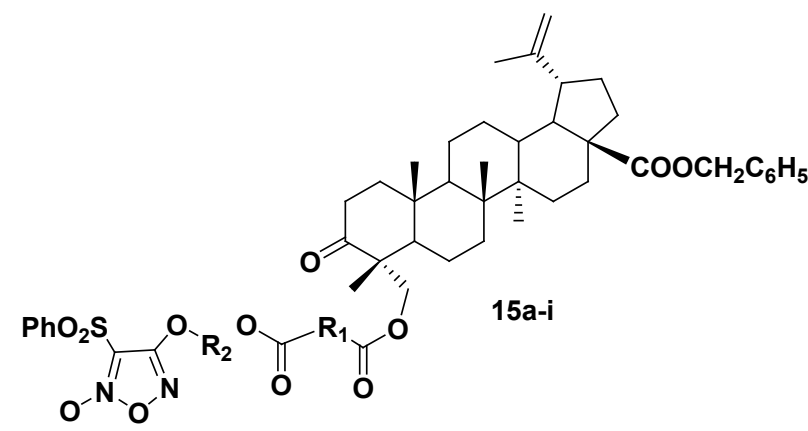

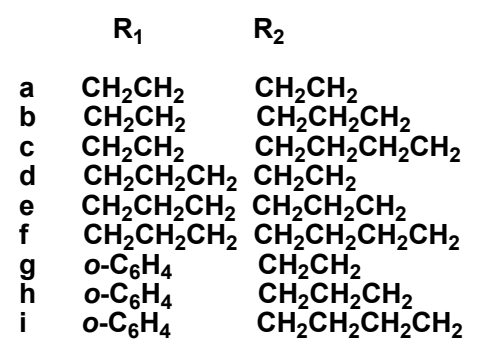

Scheme 2: General method for the synthesis of 15a-i. Reagents and conditions: (a) benzyl bromide, DMF, rt, 2h; (b) TBSCl, $\mathrm{DMAP}, \mathrm{CH}_{2} \mathrm{Cl}_{2}, \mathrm{rt}, 4 \mathrm{~h}$; (c) PCC, $\mathrm{CH}_{2} \mathrm{Cl}_{2}$, rt, 3h; (d) $10 \% \mathrm{HCl}$, acetone, rt, 2h; (e) 10a-i, EDCl, DMAP, $\mathrm{CH}_{2} \mathrm{Cl}_{2}$, rt, 8-12h.

hydroxybetulinate 14 . Treatment of 14 with intermediate furoxanbased NO donors 10a-i gave a series of hybrids 15a-i.

The synthesis of derivatives 20a-i was also started from isolated 23-hydroxybetulinic acid (2). Ketalization of 2 with 2, 2-dimethoxypropane in the presence of $\mathrm{TsOH}$ in anhydrous acetone gave cyclic ketal 16 in $84 \%$ yield. Treated with ethyl bromide and potassium carbonate in DMF at room temperature for $12 \mathrm{~h}$, esterification of 28-group was accomplished and 17 was obtained. The reduction of ester 17 with $\mathrm{LiAlH}_{4}$ in THF afforded the alcohol 18, which was subsequently reacted with $10 \mathrm{a}-\mathrm{i}$ to afford $19 \mathrm{a}-\mathrm{i}$ in moderate yields. Deprotection of $19 \mathrm{a}-\mathrm{i}$ with $10 \% \mathrm{HCl}$ in acetone at room temperature produced derivatives 20a-i (Scheme 3).

\section{Biological evaluation}

NO-releasing test: The levels of nitrate/nitrite in the lysates were determined of target compounds (15a-i and 20a-i) at $10 \mu \mathrm{mol} / \mathrm{L}$ by Griess assay through the duration of $0-150 \mathrm{~min}$. As showed in Figure 2, all the target $\mathrm{NO}$-donating derivatives were found to release different amounts of NO. In general, C-28 substituted NO-donating derivatives $(20 \mathrm{a}-\mathrm{i})$ were found to release the more amount of NO than the 3-oxo-23-hydroxybetulinic acid derivatives (15a-i). Among them, compounds $20 \mathrm{a}$ and $20 \mathrm{~b}$ showed the maximum releasing amount, with the highest level of $26.9 \mu \mathrm{mol} / \mathrm{L}$ and $25.48 \mu \mathrm{mol} / \mathrm{L}$ at the $150 \mathrm{~min}$ time point (Figures 2 and 3 ).
Cytotoxicity: To evaluate the anticancer potencies of these newly synthesized 23-hydroxybetulinic acid derivatives, the antiproliferative activities of compounds $15 \mathrm{a}-\mathrm{i}$ and $20 \mathrm{a}-\mathrm{i}$ were tested against four cancer cell lines (B16, A546, Bel-7402, K562). The present results demonstrated that nearly all synthesized NO-releasing 23-hydroxybetulinic acid derivatives can markedly inhibit the proliferation of cancer cells than their parent compounds 2 (23-hydroxybetulinic acid) and 3 (3-oxo-23hydroxybetulinic acid) (Table 1). Among them, compound 20a was the most promising derivative with an $\mathrm{IC}_{50}$ under $10 \mu \mathrm{M}$ on all tested cell lines. Noticeably, the antiproliferative activity evaluation also showed that C-28 substituted NO-donating derivatives of 23-hydroxybetulinic acid (20a-i) generally exhibited stronger activity than 3-oxo-23hydroxybetulinic acid derivatives (15a-i). These results suggested that releasing of $\mathrm{NO}$ contributed to the antiproliferative activity and higher levels of NO releasing could produce stronger activity. Moreover, preliminary structure-activity relationships displayed that the variety and length of the linkers, which connected NO donor moiety to the 23or 28-position of parent compounds, were important for compounds' activities. When $\mathrm{R}_{1}$ were aliphatic linkers, the target compounds showed stronger cytotoxicity (20a-f) than those with aromatic linkers (20g-i), meanwhile, the order of substituent $R_{2}$ for the activities was as follows: Ethyl > Propyl $>$ Butyl.

\section{Conclusion}

In summary, by coupling NO-donor moieties with natural products 

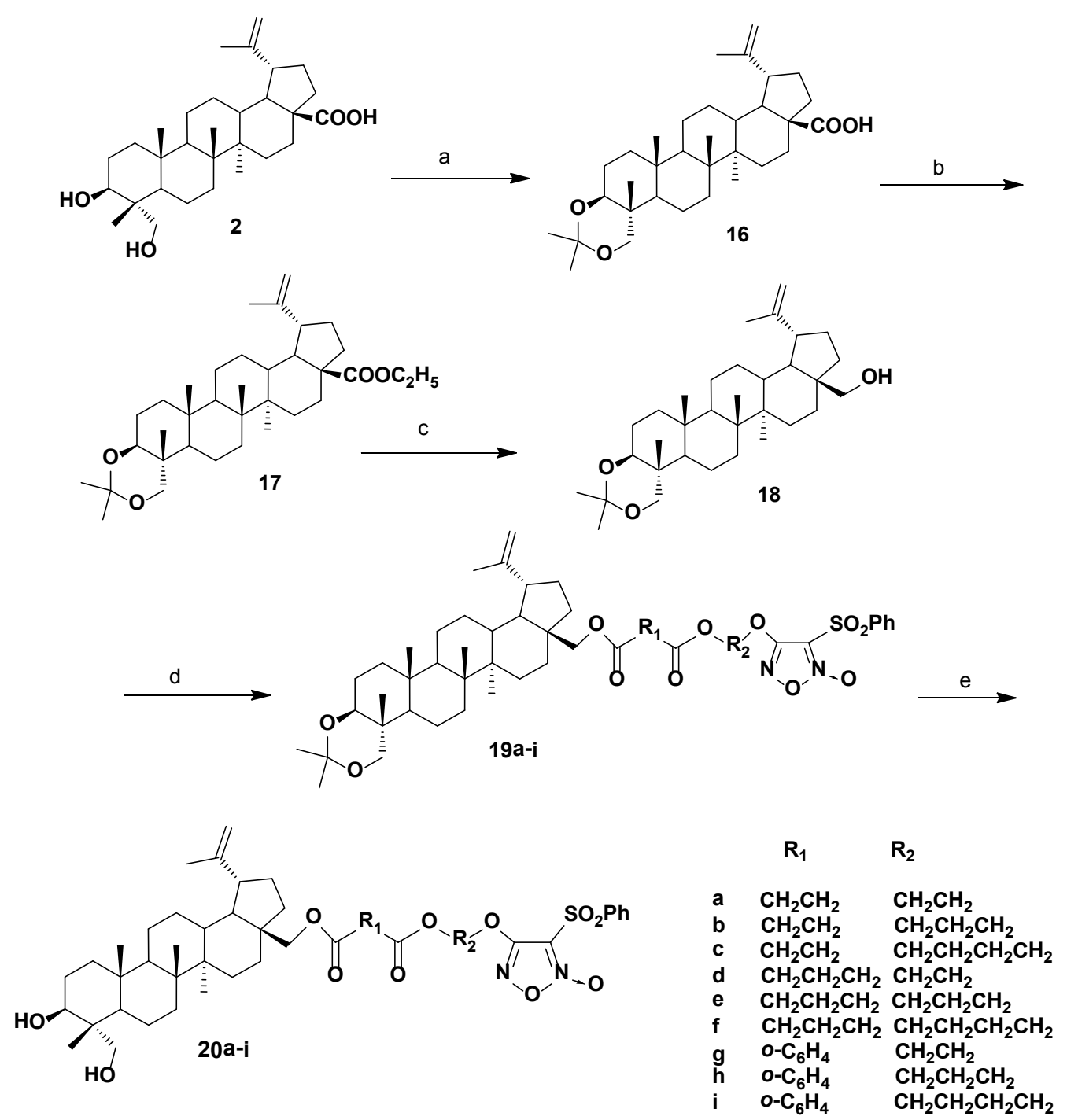

Scheme 3: General method for the synthesis of 20a-i. Reagents and conditions: (a) 2, 2-dimethoxypropane, TsOH, anhydrous acetone, reflux, 4h; (b) ethyl bromide, $\mathrm{K}_{2} \mathrm{CO}_{3}$, DMF, rt, 12h; (c) $\mathrm{LiAlH}_{4}$, THF, reflux, 4h; (d) 10a-i, EDCl, DMAP, $\mathrm{CH}_{2} \mathrm{Cl}_{2}$, rt, 8-12h; (e) $10 \% \mathrm{HCl}$, acetone, rt, $2 \mathrm{~h}$.

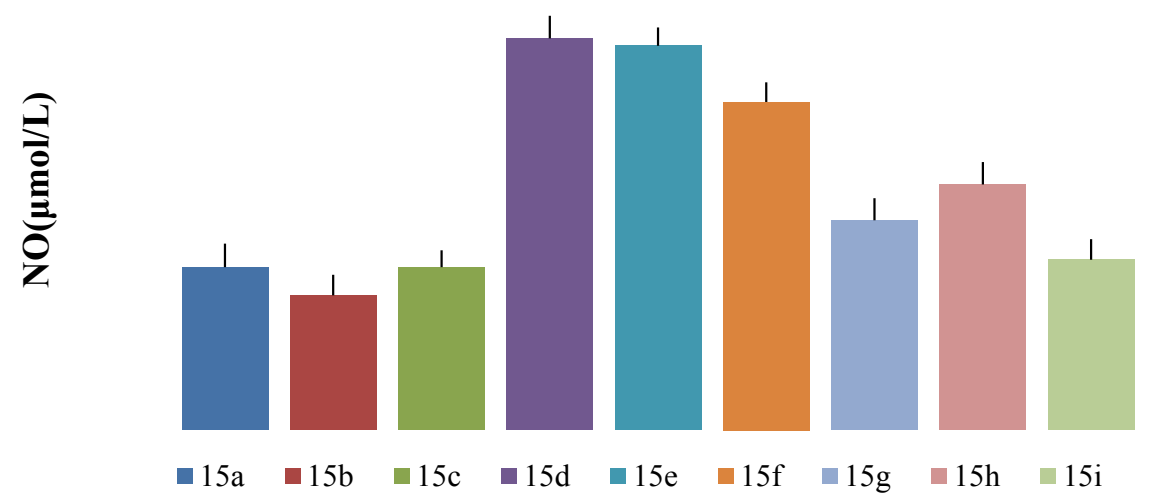

Figure 2: Variable levels of NO produced by the compounds $15 \mathrm{a}-\mathrm{i}(10 \mu \mathrm{mol} / \mathrm{L})$ at the time point of $150 \mathrm{~min}$

23-hydroxybetulinic acid and its analogue 3-oxo-23-hydroxybetulinic acid, two series of novel furozan-based nitric oxide-releasing derivatives were designed and synthesized. The NO-releasing assay indicated variable levels of NO have produced by the target compounds. Among them, compound 20a was found to release the maximum amount of $\mathrm{NO}$, and furthermore $20 \mathrm{a}$ showed to have $\mathrm{IC}_{50}$ values under $10 \mu \mathrm{M}$ 
Citation: Liu J, Sun F, Zhang H, Cai H, Yao H, et al. (2015) Synthesis and Biological Evaluation of Novel Furozan-Based Nitric Oxide-Releasing Derivatives of 23-Hydroxy Betulinic Acid and 3-oxo-23-hydroxybetulinic acid as Potential Anti-Tumor Agents. Med chem 5: 028-036. doi:10.4172/2161-0444.1000239

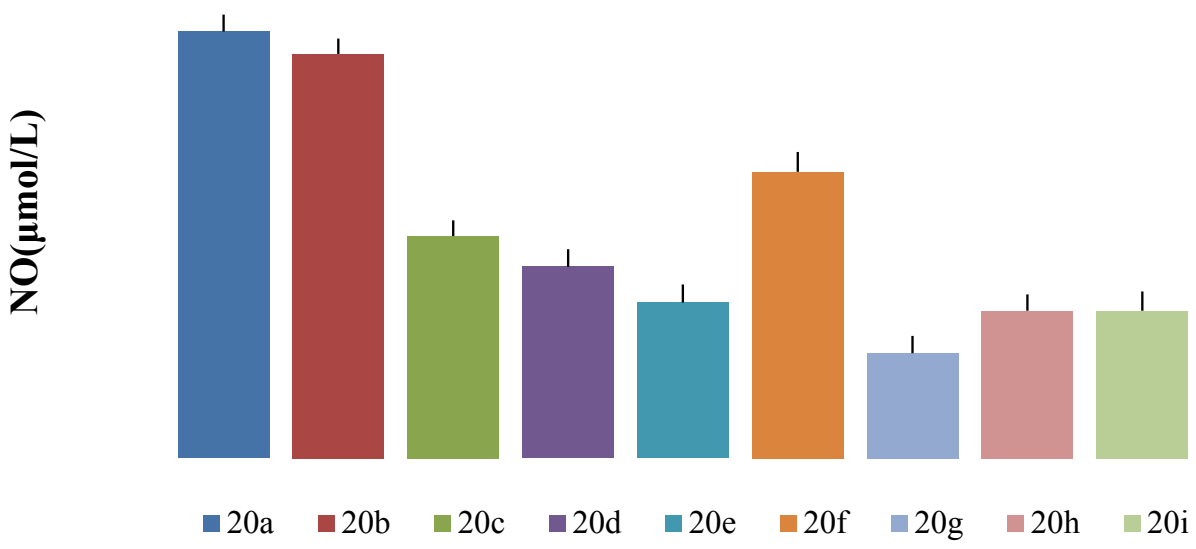

Figure 3: Variable levels of NO produced by the compounds $20 \mathrm{a}-\mathrm{i}(10 \mu \mathrm{mol} / \mathrm{L})$ at the time point of $150 \mathrm{~min}$.

\begin{tabular}{|c|c|c|c|c|}
\hline \multirow{2}{*}{ Compd. } & \multicolumn{4}{|c|}{$\mathrm{IC}_{50}(\mu \mathrm{M})$} \\
\hline & B16 & A549 & Bel-7402 & K562 \\
\hline Taxol $^{b}$ & $0.96 \pm 0.01$ & $0.72 \pm 0.04$ & $0.45 \pm 0.10$ & $0.91 \pm 0.02$ \\
\hline 2 & $29.87 \pm 3.64$ & $33.08 \pm 0.15$ & $39.67 \pm 4.22$ & $42.03 \pm 1.21$ \\
\hline 3 & $20.62 \pm 1.02$ & $29.70 \pm 0.34$ & $33.78 \pm 2.12$ & $38.33 \pm 1.31$ \\
\hline $\begin{array}{c}14 \\
15 a\end{array}$ & $\begin{array}{c}19.39 \pm 0.18 \\
7.98 \pm 0.29\end{array}$ & $\begin{array}{c}20.92 \pm 1.60 \\
9.34 \pm 0.54\end{array}$ & $\begin{array}{l}21.85 \pm 0.73 \\
11.97 \pm 0.06\end{array}$ & $\begin{array}{l}22.69 \pm 0.09 \\
12.23 \pm 0.12\end{array}$ \\
\hline $15 b$ & $10.75 \pm 0.14$ & $10.09 \pm 0.20$ & $14.87 \pm 0.24$ & $15.56 \pm 0.52$ \\
\hline $15 \mathrm{c}$ & $11.92 \pm 0.09$ & $11.27 \pm 0.33$ & $15.01 \pm 0.09$ & $16.14 \pm 0.43$ \\
\hline $15 d$ & $9.65 \pm 0.31$ & $9.60 \pm 0.14$ & $11.95 \pm 0.19$ & $12.48 \pm 0.31$ \\
\hline $15 e$ & $9.71 \pm 0.20$ & $10.62 \pm 0.11$ & $14.70 \pm 0.20$ & $16.22 \pm 0.14$ \\
\hline $15 f$ & $10.01 \pm 0.13$ & $10.33 \pm 0.07$ & $15.85 \pm 0.12$ & $16.01 \pm 0.30$ \\
\hline $15 g$ & $11.89 \pm 0.08$ & $12.91 \pm 0.05$ & $15.54 \pm 0.09$ & $17.96 \pm 0.11$ \\
\hline $15 \mathrm{~h}$ & $16.74 \pm 0.12$ & $17.74 \pm 0.09$ & $18.01 \pm 0.04$ & $19.41 \pm 0.26$ \\
\hline $15 i$ & $20.81 \pm 0.14$ & $21.87 \pm 0.28$ & $22.70 \pm 0.15$ & $25.05 \pm 0.14$ \\
\hline $20 a$ & $6.40 \pm 0.42$ & $8.05 \pm 0.12$ & $9.02 \pm 0.16$ & $8.46 \pm 0.05$ \\
\hline $20 \mathrm{~b}$ & $6.93 \pm 0.06$ & $9.71 \pm 0.30$ & $10.17 \pm 0.01$ & $10.08 \pm 0.06$ \\
\hline $20 c$ & $6.98 \pm 0.04$ & $10.03 \pm 0.05$ & $13.06 \pm 0.03$ & $12.10 \pm 0.07$ \\
\hline $20 d$ & $6.29 \pm 0.22$ & $8.78 \pm 0.19$ & $9.08 \pm 0.42$ & $9.34 \pm 0.15$ \\
\hline $20 \mathrm{e}$ & $7.13 \pm 0.16$ & $9.85 \pm 0.11$ & $10.21 \pm 0.08$ & $11.72 \pm 0.12$ \\
\hline $20 f$ & $7.97 \pm 0.14$ & $9.92 \pm 0.16$ & $13.13 \pm 0.15$ & $13.98 \pm 0.08$ \\
\hline $20 \mathrm{~g}$ & $11.15 \pm 0.31$ & $10.94 \pm 0.14$ & $14.98 \pm 0.13$ & $15.81 \pm 0.10$ \\
\hline $20 \mathrm{~h}$ & $15.16 \pm 0.18$ & $16.72 \pm 0.17$ & $17.81 \pm 0.10$ & $16.56 \pm 0.09$ \\
\hline $20 \mathrm{i}$ & $19.27 \pm 0.15$ & $20.60 \pm 0.16$ & $21.02 \pm 0.11$ & $23.14 \pm 0.08$ \\
\hline
\end{tabular}

${ }^{\mathrm{a}}$ Results are expressed as $\mathrm{IC}_{50}$ values in $\mu \mathrm{M}$. ${ }^{\mathrm{b}} \mathrm{Taxol}$ was used as a positive control.

Table 1: $I C_{50}$ values of the target compounds against four human tumor cell lines ${ }^{a}$.

on all tested human cancer cell lines, which was the most promising derivative. The present study demonstrates that introduction with NOdonor moieties at suitable positions of 23-hydroxybetulinic acid and its analogue could obtain the interesting derivatives with improved antiproliferative activity. Moreover, the assay data also revealed that the higher levels of NO-releasing could produce stronger activity. The present results may provide useful information for the subsequent design and synthesis of NO releasing derivatives of 23-hydroxybetulinic acid with improved biological response.

\section{Acknowledgements}

The project was funded by the National Natural Science Foundation of China (No. 81273377), Key Laboratory for the Chemistry and Molecular Engineering of Medicinal Resources (Guangxi Normal University), Ministry of Education of China (No. CMEMR2013-B05) and the Project Program of State Key Laboratory of Natural Medicines, China Pharmaceutical University (No.SKLNMZZCX201404).

\section{References}

1. Qian K, Yu D, Chen CH, Huang L, Morris-Natschke SL, et al. (2009) Anti-
AIDS agents. 78. Design, synthesis, metabolic stability assessment, and antiviral evaluation of novel betulinic acid derivatives as potent anti-human immunodeficiency virus (HIV) agents. J Med Chem 52: 3248-3258.

2. Dang Z, Lai W, Qian K, Ho P, Lee KH, et al. (2009) Betulinic acid derivatives as human immunodeficiency virus type 2 (HIV-2) inhibitors. J Med Chem 52: 7887-7891.

3. Csuk R, Barthel A, Kluge R, Strohl D, Kommera H, et al. (2010) Synthesis and biological evaluation of antitumour-active betulin derivatives. Bioorg Med Chem 18: $1344-1355$.

4. Zhu P, Bi Y, Xu J, Li Z, Liu J, et al. (2009) Terpenoids. III: Synthesis and biological evaluation of 23-hydroxybetulinic acid derivatives as novel inhibitors of glycogen phosphorylase. Bioorg Med Chem Lett 19: 6966-6969.

5. Bi Y, Xu J, Wu X, Ye W, Yuan S, et al. (2007) Synthesis and cytotoxic activity of 17-carboxylic acid modified 23-hydroxy betulinic acid ester derivatives. Bioorg Med Chem Lett 17: 1475-1478.

6. Lan P, Wang J, Zhang DM, Shu C, Cao HH, et al. (2011) Synthesis and antiproliferative evaluation of 23-hydroxybetulinic acid derivatives. Eur J Med Chem 46: 2490-2502. 
Citation: Liu J, Sun F, Zhang H, Cai H, Yao H, et al. (2015) Synthesis and Biological Evaluation of Novel Furozan-Based Nitric Oxide-Releasing Derivatives of 23-Hydroxy Betulinic Acid and 3-oxo-23-hydroxybetulinic acid as Potential Anti-Tumor Agents. Med chem 5: 028-036. doi:10.4172/2161-0444.1000239

7. Liu WK, Ho JC, Cheung FW, Liu BP, Ye WC, et al. (2004) Apoptotic activity of betulinic acid derivatives on murine melanoma B16 cell line. Eur J Pharmacol 498: 71-78.

8. Bi Y, Xu J, Sun F, Wu X, Ye W, et al. (2012) Synthesis and biological activity of 23-hydroxybetulinic acid C-28 ester derivatives as antitumor agent candidates. Molecules 17: 8832-8841.

9. Bi Y, Xu J, Sun F, Wu X, Ye W, et al. (2013) Synthesis and biological activity of 28-amide derivatives of 23-hydroxy betulinic Acid as antitumor agent candidates. Med Chem 9: 920-925.

10. Fukuto JM, Wink DA (1999) Nitric oxide (NO): formation and biological roles in mammalian systems. Met lons Biol Syst 36: 547-595.

11. Wink DA, Ridnour LA, Hussain SP, Harris CC (2008) The reemergence of nitric oxide and cancer. Nitric Oxide 19: 65-67.

12. Hirst D, Robson T (2010) Nitric oxide in cancer therapeutics: interaction with cytotoxic chemotherapy. Curr Pharm Des 16: 411-420.

13. Yasuda H, Yamaya M, Nakayama K, Sasaki T, Ebihara H, et al. (2006) Randomized phase II trial comparing nitroglycerin plus vinorelbine and cisplatin with vinorelbine and cisplatin alone in previously untreated stage IIIB/IV nonsmall-cell lung cancer. J Clin Oncol 24: 688-694.
14. Siemens DR, Heaton JP, Adams MA, Kawakami J, Graham CH (2009) Phase II study of nitric oxide donor for men with increasing prostate-specific antigen level after surgery or radiotherapy for prostate cancer. Urology 74: 878-883.

15. Moharram S, Zhou A, Wiebe LI, Knaus EE (2004) Design and synthesis of 3'- and 5'-O-(3-benzenesulfonylfuroxan-4-yl)-2'-deoxyuridines: biological evaluation as hybrid nitric oxide donor-nucleoside anticancer agents. J Med Chem 47: 1840-1846.

16. Maksimovic-Ivanic D, Mijatovic S, Harhaji L, Miljkovic D, Dabideen D, et al (2008) Anticancer properties of the novel nitric oxide-donating compound (S,R)-3-phenyl-4,5-dihydro-5-isoxazole acetic acid-nitric oxide in vitro and in vivo. Mol Cancer Ther 7: 510-520.

17. Li DH, Wang L, Cai H, Zhang YH, Xu JY (2012) Synthesis and biological evaluation of novel furozan-based nitric oxide-releasing derivatives of oridonin as potential anti-tumor agents. Molecules 17: 7556-7568.

18. Bai R, Yang X, Zhu Y, Zhou Z, Xie W, et al. (2012) Novel nitric oxide-releasing isochroman-4-one derivatives: Synthesis and evaluation of antihypertensive activity. Bioorg Med Chem 20: 6848-6855. 